\title{
An Investigation of Systemic Stress and Interdependencies within the Eurozone and Euro Area Countries
}

\begin{abstract}
One of the most challenging issues that economists are dealing with is the investigation of the financial turmoil in Eurozone economies. Particularly, the issue of exposing the potential crisis transmission channels has attracted considerable interest. Aiming to contribute to this literature, we construct financial stress indices on a country level and explore further the potential inter-reactions between the source causes of systemic risk. The country specific index consists of a wide number of series drawn from the money, equity and bond markets, and the banking sector of each Eurozone country. A Euro Area stress index is also provided, exploring the evolution of financial conditions for this group of countries. The investigation of the potential transmission channels is implemented through a multivariate analysis and the corresponding impulse responses' dynamics. The empirical findings suggest that countries are mostly responsive to their own financial shocks, while a degree of regionalism is also evident. That is, the peripheral countries are more susceptible to their financial stress, while the same holds for the core Eurozone countries. Additionally, in contrast to common wisdom, financial conditions in Greece and Portugal do not seem to affect the rest of the Euro Area, at least in the degree that Italy and Ireland do. These results are consistent under alternative model and sample specifications.
\end{abstract}

JEL Classifications: C43, C58, G01, G15

Keywords: Financial Crisis, Systemic Risk, Financial Stress Index, VAR 


\section{Introduction}

Since 2007, the global economy is getting through one of the most unstable periods in modern history. The problems that were raised in the sub-prime mortgage market in United States quickly spread to the global financial system and created an unprecedented financial crisis, which greatly affected the growth prospects of the world economy for many years. The interconnectedness of the various markets and national economies are so tight, that monetary authorities were forced to proceed to economic policies never applied before to such a wide scale and number of developed countries. It is not by accident that the current period is now known as the Great Recession.

The fundamental reason for reaching such levels of recession is the strong and perplexed interrelation of the financial system with the real economy. Moreover, the fact that financial markets consist of a number of actual different markets, like the banking market, the bond market, money market and so on, each one driven by its own distinctive forces, makes things even more complex and difficult for assessing the underlying causes of financial turmoils and deciding on the optimal policies for the alleviation of market instabilities. Central bank authorities employ monetary policy measures, in order to intervene and stabilize the economy, while the financial stability and financial stress assessment was a recent addition to their mandate. In any case, even the so-called monetary policy transmission channel is not, yet, thoroughly evaluated and tracked down the different ways through which it can affect the aforementioned. In order to perform such an evaluation, a measure able to identify financial system impairments is necessary. Hence, there is a need for using financial stress indices, able to clearly depict systemic risk.

Another reason, rendering the employment of such financial stress measures necessary, is the fact that the same nature of financial crises has been multifaceted. As it has been evident in the last few years, during Great Recession, the sources and causes of a financial crisis can significantly vary, in accordance to changes taking place in the financial market conditions and investors sentiment. For instance, the current financial crisis begun from a, relatively small, uninteresting, financial market, the sub-prime mortgage market in the United States. Soon, it has infected several markets and economies around the world, with this crisis reaching its peak with the 
Lehman Brothers collapse in September 2008. This situation brought a major disruption in money markets, as well as the interbank funding market, leading to a drying up of liquidity in a global level. In turn, this had major repercussions on capital struggling companies, households and countries, brining up more transformation of this crisis into a banking one and, lately, a sovereign debt crisis. As it is also emphasized by Sandahl et. al (2011), an authoritative study of the whole financial system, is of utmost importance and can be accomplished using financial stress measures. In this way, a clear and timely depiction of the prevailing conditions in each financial market is possible, while it is also an efficient way to assess the marketwide systemic risk for the economy. Finally, these indices can be used to evaluate the effectiveness of the monetary policies followed by central banks, since tools used by the latter are integral parts of the aggregate financial stress indexes.

As it has been clear from the previous discussion, there is great scope for the implementation of financial stress indices, especially in the present situation, where the need for indicators of systemic-wide financial instabilities is extremely important. Here, we are going to construct a series of financial stress indicators, in order to analyze the current Eurozone crisis. This is an important motivation for this piece of research, since the unprecedented level of financial and sovereign turmoil in the Euro Area should be investigated and scrutinized. In order to do it, we employ a wide number of indicators, originated from the most important financial markets. These are the banking sector, the money, equity and bond market of each one of the eleven original Eurozone countries ${ }^{1}$. In this way, we construct five stress indices for each country (four sectorial, one country-wide), while an index for the whole union is also provided. The weighting scheme used to aggregate the individual indexes is the variance-equal approach, where each single indicator contributes to the aggregate index equivalently.

In the second stage of this empirical assessment of the Eurozone crisis, we provide initial evidence on the implied interrelation between the markets and the countries financial (in)-stability. The existence of trade and tight financial connections between euro currency countries, along with the existence of a unified monetary authority, deciding on the kind of monetary policies followed by all these countries,

\footnotetext{
${ }^{1}$ Luxembourg is not included, since it is a small economy, without major interactions with the other core Eurozone countries. Also, even though Greece joined the common currency a bit later (2001), its alleged contribution to the current crisis renders its inclusion to the analysis quite important.
} 
justifies and strengthens the necessity of such an econometric investigation. The provision of such empirical evidence leads to the establishment of interactions among the markets and the countries under exploration, providing further evidence in one of the hottest debates of concurrent financial literature. That is, the existence of channels of interdependence and contagion of the financial crisis from one country to another. With our work here, we expand the literature in many ways. First, it is possible to examine channels of crisis transmission using aggregate indexes of systemic risk, on a cross country level. Thus, a more detailed analysis of potential stress sources is possible. Additionally, such an empirical evaluation of intra-Euro area interdependencies is useful for policy purposes, since the detailed and exhaustive indagation of the aforementioned indices and interrelations prove the necessity of different kind of policies in different countries and cases of financial upheavals. Moreover, these stress indexes are ideal as early warning indicators of forthcoming financial abnormalities, since their advantage is the timely information they provide for the current state of the financial markets.

The empirical work involves the usage of vector autoregressive (VAR, hereafter) models, specifically impulse response analysis, in order to examine the interrelations of the aforementioned economies, through the financial stress indices. A plethora of empirical findings are provided, regarding the Euro area financial crisis interrelations, the driving forces behind it and its main propagators.

This paper is organized as follows. In section two, a discussion of the most important papers, dealing with the measurement of European countries financial stress is provided. Then, the dataset employed is presented, emphasizing the usefulness and importance of the indicators included in the systemic stress indexes. Moreover, the econometric methodology adopted is presented. In section four, the Euro wide index is discussed, together with its features and its effectiveness as tool of financial system safeguarding. Part five provides an exposition and justification of the econometric results and part six provides further empirical evidence and robustness checks. The last part recaps and concludes. 


\section{Financial Stress Measures for Eurozone and European Countries: An account of the relevant literature}

The literature on financial stress (or, as some of the authors call them, financial fragility) indices (FSI), has mushroomed the last decade. It is a branch of the research developed as a continuation of the early warning indicators (EWI) literature, models that have been used in previous empirical work on, mainly, currency and banking crises episodes. With the FSI approach, a series with continuous values is provided, offering a timely illustration of the market conditions, thus, better monitoring of the financial system is possible.

The development of financial stress indices was initiated from economists in developed economies. It is reasonable, since the necessity for such tools was stronger to the economies mostly harshly hit by the recent financial crisis. Additionally, a great deal of such research is accomplished by economists in policy making institutions, such as IMF, OECD and central banks. The majority of the papers cope with the US economy, while there is growing interest for Eurozone's case.

Illing and Liu (2006) outbid for the creation of an FSI as a well-suited index of financial stress for developed economies, compared to other early warning indicators. The authors are mainly interested into three tasks here. First, they want to specify which time periods can be considered as stress periods for the Canadian economy, then which variables they should use to create their FSI and, finally, which one of the different FSI's they compute is the most efficient. For the first task, they conducted a survey within the Bank of Canada economists, collecting answers on a series of questions. Then, they experiment with different methodologies and a series of variables $^{2}$, in order to develop a financial stress index for the Canadian economy. Trying to further refine their work, the authors apply different weighting scheme on their variables, so as to identify which one leads to the creation of a single FSI that outperform the rest of them. They try four methodologies: factor analysis (which uses weighted linear combinations of the variables), credit weights (the contribution of each market to the total credit available in the Canadian economy is the important factor here), the variance-equal weights approach (by standardizing each variable by

\footnotetext{
${ }^{2}$ These are financial, banking, macroeconomics and debt variables. For details, please consult the paper.
} 
subtracting its mean and dividing the result by its standard deviation) and a cumulative distribution function approach. Based on the different indices' performance (in terms of Type-I and Type-II errors, as defined by their survey for extreme events in the Canadian economy), they conclude that the best financial stress index seem to be the credit-weighted one, although, in individual markets, some other indexes might perform quite well.

Considerable effort is being made to introduce such policy tools in the central banks' financial monitoring ammunition, especially from economists of the US Federal Reserve System. A number of different methodological approach is used for the construction of these indices. For instance, the Kansas City Financial Stress Index (KCFSI), as developed by Hakkio and Keeton (2009) is very close to ours. Their index consists of eleven variables, representing one or more of the features financial stress has ${ }^{3}$.These are the TED spread, the 2-years swap spread (which is the difference between a floating rate payment, based on LIBOR, from a fixed rate payment, which derives from the treasury bill rate, augmented by a premium), the yield differential of previously issued securities from the most recently issued one, of the same maturity (called as the off-the-run - on-the-run ten year treasury spread). Additionally, a number of bond spreads are also included in this index, together with the correlation of the stock returns with the two-year governmental bond yield, the implied volatility of the stock prices. Brave and Butter (2011) use a dynamic factor model that allows the inclusion of unbalanced series in the index. In this way, they take into account one hundred financial indicators for the US economy, with different frequency and time coverage (47 of them are weekly, 29 monthly and 24 quarterly series, covering the period 1971-2010). Their work is the foundation for the creation of the Chicago Fed FSI. Oet et al. (2010 and 2011) worked on the same type of distress indices and came up with the Cleveland FED FSI ${ }^{4}$.

A considerable amount of research has been devoted to the development of such aggregate distress indices for developing economies as well. For instance, Morales and Estrada (2010) compute an FSI for Colombia. They include banks' profitability and probabilities of default, as components of their indexes, together with a series of variables that sketch out the capital, liquidity and credit risk conditions of

\footnotetext{
3 "Flight to quality" and "Flight to liquidity".

${ }^{4}$ A thorough review of the US financial stress indexes is provided by Kliesen et al. (2012), together with a forecasting exercise.
} 
the country. Additionally, the authors construct one index for each different type of financial institutions that operate in the Colombian market ${ }^{5}$. Additionally, they apply three different weighting schemes; the most commonly used variance-equal weighting, principal components analysis and count data modelling. According to this work, the FSI behaviour, irrespective of the weights applied, is similar and accurately represents the financial instability period of the Colombian economy on late 90's. The same holds for the institutional indices as well. Similar work on systemic risk metrics for emerging economies can be found to Debuque-Gonzales et al. (2013) and Osorio et al. (2011), among others.

A first attempt to construct an FSI for the Euro area has been made by Grimaldi (2010). Based on the indicators proposed by Nelson and Perli (2006), the author has a threefold intention: to specify the actual stress period for the Euro zone markets, to compute relevantly accurate indices and test whether her index can work as a leading indicator of stressful events. For the first goal, the author employs information contained in European Central Bank's communication (using ECB's Monthly Bulletins) to help her measuring financial market stress. In this way, she indicates periods that seem to reflect periods of financial upheaval ${ }^{6}$. In order to verify these findings, a financial fragility index is built, using sixteen variables from the bond, banking, equity and money markets. Specifically, the difference between each Euro zone's country long term bond yields from the German one represents the sovereign bond spreads. Additionally, bank equity prices index and the AA-rated corporate bond spreads are used as proxies of the conditions prevailing in the banking sector. General equity index, actual earnings per share and equities risk premium were chosen for the equity market component of the indicator. Regarding money markets, one and three month Euribor-EONIA rates spreads, together with the spread of the main refinancing rate and the two year bond yield were utilized. All these variables were then integrated into two indices, the first being the weighted (by the inverse of each variable's variance) average of them, while the second one is the rate of change. Finally, these two indexes were combined into a single indicator, with the help of a logit model, so that extraction of information on stressful periods to be more effective.

\footnotetext{
${ }^{5}$ These are commercial banks, mortgage banks, commercial financial companies and financial cooperatives. Their sample is comprised of 170 institutions, for the period 1995.1-2008.11.

${ }^{6}$ This has been done by counting how many times specific words appear in the bank's bulletin.
} 
Using weekly data for the period July 1999 to October 2009, the contingent financial stress index works well and captures crises periods of the last 10 years. Grimaldi (2010) confirms the good functionality of her FSI, comparing its performance with the VSTOXX index ${ }^{7}$ and the signaling methodology, popularized by Kaminsky, Lizondo and Reinhart (1998).

Beyond the construction of aggregate Eurozone- wide financial stress indices, some economists have proceeded to the creation of country - specific indices. Especially for countries that are in the centre of the current debt crisis, the interest in examining their financial conditions is quite intensive. For instance, Louzis and Vouldis (2011) compute an FSI for Greece, using both market and balance sheet data. According to the authors, such an index is useful for, both, policy design (through the identification of the state of the financial system), as well as for the dating and prediction of financial stress. The authors follow the framework proposed by Hollo et al. (2012), who use the components' correlation, in order to assess systemic stress. Moreover, they extend this approach, by using multivariate GARCH modeling, so that they can be able to capture time-varying correlations of the index components. The choice of the variables that are included in their analysis is based on their relevance to economic theory and the respective empirical literature. Thus, they focus on series capturing systemic stress, increased uncertainty and chancing expectations in the financial markets. Their set of variables consists of the following segments: fundamentals of the Greek economy (the sovereign bond spread, the realized volatility of the Greek government bond and the correlation of the Greek stocks returns with the German Bund), variables from the Greek banking sector (banks stock index, the realized volatility of the banks index, the bank equities' beta, the bank bond spreads which is the spread of the bond yields issued by Greek banks from the German governmental bond), the equities market and the money market (the TED spread). Turning to the authors' construction methodology for their index, they first use principal components analysis to construct sub-indices for the aforementioned groups of variables. They do this, using the first principal component in each case. Then, as it was mentioned above, the framework by Hollow et al. (2012) is followed. The authors consider portfolio based approach to aggregate the sub-indices into a common FSI. The rationale is that, whenever correlation among the different market increases,

\footnotetext{
${ }^{7}$ It is an implied volatility index, based on equity option prices.
} 
financial upheaval increases as well. In order to evaluate the usefulness of their FSI, the authors graphically inspect its behavior. There is evidence that the index can accurately capture periods of financial turmoil, while the sub-indices inspection reveals the relevant importance of the different market segments. According to this decomposition, the money market seems to be the most important contributor to the present crisis, while economic fundamentals are also quite important. It is interesting that the banks balance sheet index minimally affect the level of financial risk, probably because of the limited exposure of Greek banks to "toxic assets" effects. A final evaluation of the index is provided from a survey that was conducted among financial experts of the Greek financial market.

A similar effort to the previous one is made by Angelopoulou et al. (2012). The authors try to construct financial conditions indexes for the Euro area as a whole, together with indices for some Eurozone countries (Germany, Greece, Ireland, Portugal, Spain). In their case, three different types of indices are formulated, one including monetary variables (so that the monetary policy effect can be evaluated), one without the aforementioned variables and, finally, one which is the difference between the previous one and an index computed through a principal components analysis, where the monetary policy loading are set to zero by the authors. Proceeding to their data selection, the authors choose twenty four variables, for the Eurozone aggregate index, while twenty are those included in the country specific ones. The choice is driven from, both, data availability, as well as based on the previous literature on this research topic. In this line of thought, the researchers incorporate several types of interest rate spreads (such as spreads between different types of loans and deposits), together with spreads from the interbank market (for instance, the three-month Euribor from the EONIA rate). Moreover, a number of quantity indicators are also included, like the value of debt securities issued by non-financial corporations and monetary institutions. Finally, a number of survey series (related to banks' liquidity position and consumer creditworthiness), along with series representing the volatility risk of stock and bond prices are also included in their stress indices. In order to create their aggregate indexes, these authors proceed to their analysis based on principal components methodology. Angelopoulou et al. (2012) use the first three principal components for the Euro Area, while for the country specific indices the first four. The decision criterion is that the components included in the analysis to explain, about, $70 \%$ of the total variance. Then, the contribution of 
each one of the series in the final index is calculating, based on the loading of them in each component, weighted according to the level of variance explained by each one of these principal components. The final step is to weight the computed indices by the exact share of variance that the components which are included in the analysis explain. Based on the loading weights, the authors suggest that each principal component represent different kind of influence in the financial conditions. For instance, it is evident that the most important variables in the first principal component are the survey variables, while interbank market spreads and bond volatility are also important. On the other hand, bank credit variables and securities issuance ones seem to be more important in the second component, while the third component emphasizes the role of the spreads between loans and deposits. In the weighted loading case, the magnitude of the variables is, in general terms, as it is expected to be. By inspecting the FCIs graphs, there seems to be a tendency to loosen financial conditions, since the beginning of the sample (2003, with end of 2011 to be the end of the sample here $)^{8}$. This situation prevailed until early 2007, when the financial conditions began to worsen. In the case of the countries FCIs, it is evident the existence of asymmetric responses to the varying financial conditions. The situation in Germany diverges from the other countries under investigation, both in the pre-crisis period and in the postcrisis period. In the last two years of the sample (since 2010), situation worsens in Greece and Portugal mainly, while in Germany are improved. Generally, it is shown that monetary policy effects are not unanimous in the whole Eurozone, something that indicates the need for particular attention on the kind of policies prescriptions proposed by ECB.

\section{Data and Empirical Methodology}

\subsection{Dataset Description}

\footnotetext{
${ }^{8}$ in the case of Financial Conditions Index, loosening conditions are captured by increasing level of the index, while tighter conditions by decreasing level of it.
} 
In order to depict the effects of a financial turmoil in a systemic wide level, we employ data from four markets, for each one of the initial Eurozone members ${ }^{9}$ : the banking sector, money market, equity market and bond market. In all cases, we use monthly data, ranging from January 2004 until August 2011. The selection of variables is based, partly, on previous work done on systemic risk issues, as well as on variables that are important on the formulation of the state of the financial systems. In the following table, we provide an overview of the series used. An important innovation here, compared to the previous literature in this area is the inclusion of an extensive number of balance sheet data, for a wide number of European banks. The multifaceted nature of the current crisis that hit hard many major banks around Europe, in many cases without obvious underlying reasons, stated the examination of balance sheet indicators very crucial. Depending on data availability, the number of banks by each country that has been incorporated to the construction of the bank and the aggregate index varies (from one bank to Belgium and Netherlands to eight for Greece).

In any case, our sample consists of 41 banks, covering major banks from all countries and banks with big market capitalization, size and market power. The limitation on the number of the financial institutions is dictated by the fact that many of them are not listed to a stock exchange and, as a consequence, there is a lack of data on their market performance. There are five groups of variables for each one of the bank, while the last one, called "overall market conditions", represent the general conditions prevailing in the banking sector of each country (here, the series are market wide, not bank specific ones). So, the number of the indicators included for the banking stress index of each country varies from 27 variables (in cases where only one bank for a country is used) to 181 variables (in the case of Greek banks). The data are retrieved from various sources, but most of the balance sheet ones are from Bureau Van Dijk Bankscope database. Since most of these series are provided in yearly or quarterly basis, they are interpolated into monthly frequency.

\footnotetext{
${ }^{9}$ These are: Austria, Belgium, Finland, France, Germany, Greece (since 2001), Ireland, Italy, Netherlands, Portugal and Spain.
} 
Table 1: Indicators of Financial Stress

\begin{tabular}{|c|c|c|}
\hline \multicolumn{3}{|c|}{ Variables Used in Financial Stress Indices } \\
\hline \multicolumn{3}{|c|}{ Banking Sector } \\
\hline Operational/ Profitability & Liquidity & Assets Quality \\
\hline $\begin{array}{c}\text { ROA } \\
\text { ROE } \\
\text { EPS } \\
\text { P/E } \\
\text { Inefficiency } \\
\text { Net Interest Margin }\end{array}$ & $\begin{array}{l}\text { Interbank Ratio } \\
\text { Net Loans/Total Assets } \\
\text { Loans/Deposits } \\
\text { Total Liabilities/Liquid Assets } \\
\text { Interbank Funds/Liquid Assets }\end{array}$ & $\begin{array}{c}\text { NPL/Gross Loans } \\
\text { Loan Loss Reserves/Total Loans } \\
\text { Loan Loss Reserves/Impaired Loans } \\
\text { Size } \\
\text { Market Power }\end{array}$ \\
\hline Capital Adequacy & Volatility Risk & Overall Market Conditions \\
\hline $\begin{array}{l}\text { Tier } 1 \text { Capital Ratio } \\
\text { Total Capital Ratio }\end{array}$ & $\begin{array}{l}\text { Stock Returns } \\
\text { Dividend Yield } \\
\text { Market Value } \\
\text { Turnover by Volume }\end{array}$ & $\begin{array}{c}\text { Deposit Gap } \\
\text { Loan Gap } \\
\text { Bank Equities Realized Volatility } \\
\text { Banking Sector Beta } \\
\text { Bank Equities Returns }\end{array}$ \\
\hline \multicolumn{3}{|c|}{ Money Market } \\
\hline $\begin{array}{l}\text { TED Spread } \\
\text { Inverted Term Spread } \\
\text { Treasury Bill Realized Volatility } \\
\text { Main Refinancing Rate - } 2 \mathrm{yr} \\
\text { Government Bond Yield }\end{array}$ & & $\begin{array}{c}\text { M2 Growth } \\
\text { M2/Foreign Exchange Reserves } \\
\text { Intermediation Rate } \\
\text { Main Refinancing Rate - 5yr Government Bond Yield }\end{array}$ \\
\hline Equity Market & & Bond Market \\
\hline $\begin{array}{c}\text { Stock Returns } \\
\text { EPS } \\
\text { Dividend Yield } \\
\text { P/E } \\
\text { Stocks Realized Volatility }\end{array}$ & & $\begin{array}{c}\text { Sovereign Spread } \\
\text { Government Bond Realized Volatility } \\
\text { Corporate Spread } \\
\text { Government Bond Duration } \\
\text { Stock Returns/German Bund Realized Correlation }\end{array}$ \\
\hline
\end{tabular}

In the first category, there are series representing the operational characteristics and banks' profitability determinants. Here, returns on assets (ROA), as well as returns on equity (ROE) are crucial ratios for the evaluation of the smooth performance of a bank. As indicated by Morales and Estrada (2010), these two variables depict the efficiency of the banks on employing their available funds, while on the same time are accurate representations of the level of profits they produce. Thus, it is evident the importance of their inclusion in this fragility index, since banks with low level of profitability are more susceptible to default. Additionally, regarding ROE, Louzis et. al (2012) emphasize its importance as a measure of the cost efficiency and of the efficacy with which banks use their internal and external financing. On the other hand, earning per share (EPS) ratio and P/E ratio are also indicative of the financial health of these institutions. The former is a well known metric of profitability, the behavior of which is indicative of the banks' ability to cope 
with strenuous financial conditions ${ }^{10}$. Price-to-earnings ratio works in the same fashion. Since a decline of the P/E ratio would represent decreasing profitability for a financial institution, it is reasonable to include this variable with a negative sign in the following empirical work. Inefficiency, which is the ratio of operating expenses with operating income, is a very efficient proxy for how prudent a bank is. In their work for the determinants of non performing loans, Louzis et. al (2012) propose the use of inefficiency as a measure of banks management quality, in terms of their ability to monitor and avoid excessive funding to default - like investments. Thus, it is natural to include this indicator to our dataset. Finally, net interest margin, defined as the bank's income from its intermediation activities, is also included in the set of indicators as an important contributor to the banks financial robustness.

The second group of variables consists of liquidity indicators. The interbank ratio represents the value of funds a bank lent to other banks over the money it has borrowed by others. In this way, interbank ratio is a good proxy for financial instability transmission, since it represents the exposure of each bank to funds from other banks. The ratio of net loans to total assets is a ratio of dual nature, in the sense that it, concurrently, depicts the degree of liquidity of an economy (since the higher the financial leverage of a banking system, the higher should be this ratio), but on the same time it is a variable mirrored the banks portfolio quality and sustainability. Thus, it is a metric with ambiguous sign, regarding its contribution to excessive systemic risk or not. On the other hand, loans-to-deposits ratio is another important variate. A higher value of this testifies lower liquidity available for banks, while the exposure to default risk is, also, greater. It can be considered as a good funding proxy, as well, if its usefulness as a measure is viewed from the economy's aspect. This set of indicators concludes with two liquidity risk ratios, namely the total liabilities to liquid assets and the interbank funds - liquid assets one ${ }^{11}$. The reason behind the inclusion of these two indicators has, mostly, to do with their importance for the capability of a bank to cope with situations of increasing default rates and deepening recession of the economy. In this sense, the higher these ratios are, the more vulnerable the banks become.

\footnotetext{
${ }^{10}$ Grimaldi (2010) and Louzis and Vouldis (2012) pinpoint the negative relation of EPS ratio with cases of increasing financial stress. Thus, we incorporate it with negative sign in the stress indexes construction.

${ }^{11}$ Morales, M. and Estrada D. (2010), "A Financial Stability Index for Colombia”, Annals of Finance, 6:555-581
} 
Moreover, the quality of the assets a bank has to its portfolio is of utmost importance for its survival in an uncertain financial environment. As it is well known, credit risk is the main type or risk that banks must manage and be cautious towards it. Thus, the reserves of such a financial institution, which are capital provisions for cases of bad loans writing offs, compared to its loans portfolio (both total and the impaired ones) is crucial. As Puddu (2008) indicates, these measures are proxies of the quality deterioration in banks' balance sheets ${ }^{12}$. Thus, a positive contribution on the crisis index should be expected. On the same time, the credit risk they face is negatively related their size and market power ${ }^{13}$. Finally, the analogy of non performing loans to total loans is, clearly, evident of the quality of loans in a bank's portfolio and a positive sign is expected for its contribution to the financial stress index.

The capital adequacy indicators are those dictated by the Basel Accord, related to the minimum capital needed for the default risk coverage by the banks. In the group of volatility risk variables, we include those series which abnormal behavior renders the bank vulnerable to market risks and instabilities. For instance, higher stock returns indicate heightened uncertainty among investors, something that can have serious effects on the bank's operation and viability. Moreover, dividend yield can, potentially, give negative signal for a bank, since it is negatively related to the robustness of a financial institution's fundamentals. Market value and turnover by volume are, also, closely related to market sentiment, with a feedback loop existing between their level and market uncertainty (and, of course, with the level of financial stress). Turnover by volume is defined as the number of a bank's equities traded on any particular date, usually given in thousands of stocks. Thus, increasing turnover for a bank's equity provides signals against this institution's viability and vigor.

General conditions of the banking sector of each Euro Area economy are sketched out by the last bunch of variables used for this market. In the same fashion as Louzis and Vouldis (2012), we employ the so called deposit and loan gaps. These are produced, using the Hodrick - Prescott filter, proposed by the aforementioned economists in 1997, in order to extract the cyclical component of the deposits and

\footnotetext{
12 The tendency to increase loan loss reserves is indication of worsening balance sheets, since banks in this way admit their concern on losses on their loans portfolio. On the same time, it can be considered as a sign of prudence from their side. In any case, in the literature, the first case is considered as more important and effective on the role of this indicator.

${ }^{13}$ Size is the value of each bank's assets, compared to market's total, while market power is related to loans given, to total value of them. For details, consult Louzis et. al (2012).
} 
loans of each bank from the trend element of them. This is a useful approach, indicating the cumulative dynamics of these two important elements of banks balance sheets. Increasing deposit gap is indication of deposit shortage, while a loan gap can be interpreted as higher market uncertainty and, thus, reluctance from the banks to provide loans. The level of investors' uncertainty is depicted by the realized volatility of the bank equities index for each country. Increasing values of this volatility measure represent increasing financial upheaval. A very common component for stress indices is the beta coefficient of the banking sector index ${ }^{14}$. High beta values are an indication of banking sector equities to be considered as riskier and, thus, investors' sentiment is against them. Finally, we also include the bank sector index returns, in the same logic as the stock price returns of the individual banks.

Proceeding with the discussion of the variables included in the other three markets investigated here, we begin with the money market. Here, eight variables are included in the dataset. One of the most frequently used series for financial stress indices construction is the so called TED spread. It is the difference of the uncovered interbank short term lending towards a short term treasury bill (usually the 90-days treasury bill). For the case of Eurozone, the former is the well known 3-month Euribor, which is the benchmark and basic rate based on what European banks offer funds in the interbank market. The use of this indicator is popular, since it represents both, counterparty risk and liquidity risk in the markets. In times of increasing uncertainty and financial instability, problems of adverse selection can rise, since lending banks would be unable to identify the most financially reliable banks while the need for funds can be excessively high. Thus, increasing TED spread is expected for times of heightening financial fragility. Additionally, the slope of the yield curve is used, sometimes called inverted term spread. It is nothing more than the difference of the yield of short -term governmental securities from the long term ones (here, the 3 month treasury bill from the 10 year government bond yield is used). The reason for including this variable has to do with the well justified, from the literature, ability of the yield curve to work as leading indicator of the real economic activity ${ }^{15}$. Hence, a forthcoming recession greatly affects the financial position of many debt ridden firms and the default risk is highly exacerbated. Additionally, it is a good indicator of the

\footnotetext{
${ }^{14}$ It is used in most cases of FSI construction. For instance in Louzis and Vouldis (2012), Slingenberg and de Haan (2011), Melvin and Taylor (2009) and many others.

${ }^{15}$ Mishkin, F. S. and Estrella, A. (1998), "Predicting U.S. Recessions: Financial Variables as Leading Indicators", The Review of Economics and Statistics, vol. 80(1): pp. 45-61
} 
investors' expectations on future short term interest rates. Since, during period of financial turmoil, the need for liquidity is higher and more intensive, investors turn to more easily liquidated securities, like the treasury bills. In turn, this affects their returns, expanding the spread between the aforementioned securities. The next two indicators, namely the spread of the main European refinancing rate from the two and three - year government bond yields are also strong indicators of monetary liquidity. As it is emphasized by Grimaldi (2010), the decrease of these spreads represents liquidity worsening situation. For this reason, we incorporate these two indicators with negative signs in the analysis, so that their deterioration can indicate increasing level of financial suffocation. Growth of money supply and the ratio of money stock to the economy's foreign exchange reserves are two series, coming from the prior literature on early warning indicators of currency and banking crises. As it is evident from Kaminsky et al. (1998) and Demirguc-Kunt and Detragiache (1998), the previously mentioned variables are among the successful leading indicators for forthcoming currency and banking crises. Since both can produce signals, long before the actual outbreak of a crisis event, and since they both represent values of utmost importance for the economy's growth rate and the total credit available, their inclusion to this dataset is advantageous. The realized volatility of the treasury bill rate is incorporated here, representing the uncertainty and excessive abnormality of the money market, since treasury bills are those securities with the highest value of transactions in short term borrowing markets. Finally, the intermediation spread is the difference between lending rate and deposit rate. Even though, it is a variable that is, partly, reflects the level of profitability of financial intermediaries, it is contained in this group of variables, since it is also a strong indication of the available sources of credit and its supply level into the economy.

In the equity market group, we include five variables. Firstly, the stock returns are incorporated, with negative signs since the large negative returns are those that create the greatest uncertainty for investors. Then, the earnings to price ratio (with a negative signs in the formation of the stress indices, because of the reasons stated in the banking sector analysis) and the P/E ratio are chosen, as major variables representing the profitability and health of the market participants. Moreover, dividend yield is another series, reflecting the robustness of the stock market. Thus, its inclusion is important, since its behavior is a sign of listed companies' ability to cope with financial strain. This set of indexes is concluded with the realized volatility of 
the stock markets' general indexes. As in all previous cases, the realized volatility is computed, using daily data, as the sum of squared logarithmic returns, adjusted by the trading days of each year in the sample.

The last set of series has to do with the bond markets of Euro Area countries. An important contributor in this group is the sovereign bond spread, calculated as the difference between each country's long term government bond yields from the German long term bond yield. It is reasonable to follow this convention, since the German economy is considered as the strongest, most prudent economy of the union ${ }^{16}$. This indicator represents the sovereign risk each country faces. Then, the realized volatility of each country's long term bond is used, again using daily data on their yields. Increasing uncertainty and flight-to-quality phenomena, sprung by excessive systemic stress level, would lead to higher volatility. The corporate bond spread, defined as the spread between the corporate bond yield from the governmental one. In this way, the default risk and inability of firms in times of financial strain to acquire the necessary capital for their operation, is depicted. An innovative feature of the dataset is the use of government bond duration. It is an interesting variable, since it represents the sensitivity of bonds prices to changes in interest rates. In general, it is expected to have a negative relation between bond duration and interest rates. Based on the volatile behavior of interest rates in periods of financial uncertainty, there not seems to be a consensus on the kind of effects a financially instable period have on bonds duration. On the other hand, recent research by Lee et al. (2012) and Lee et al. (2011) indicates the strong effect that excessive sovereign risk has on governmental bonds. According to these authors, the duration decreases, especially for bond with lower ratings. As a result, the heightening investors' concerns on possible default of debt strangled countries with low rated bonds, should lead to lower duration for the bonds of these troubled countries. The last indicator here is the so called realized correlation of each country's stock returns with the German Bund. With this variate, we aim to include the effects of the financial instability on the investors' decision to withdraw their invested funds from a troubled economy to one that is perceived as safe (in Eurozone's case, Germany). Again, this indicator is computed using daily data on our sample's general stock indices and the German long term government bond yield.

\footnotetext{
${ }^{16}$ For the case of the Germany itself, we just include the yield of its 10 year governmental bond.
} 


\subsection{Methodological Approach}

Our decision, regarding the construction methodology of our financial stress indices, follows the literature. We intend to calculate the FSIs based on the equally weighted approach. According to this approach, an equal weight is attributed to all variables in each of the markets. In this way, the sectoral indices are computed, while the same approach is followed for the country - wide one. It should be emphasized here the fact that each series is demeaned and divided by its standard deviation. This is useful for two reasons: it helps avoiding problems of mis-measurement in the series, while it is also a necessary transformation, in order to evaluate the size of the financial instability in each time period, in terms of deviation from the mean value of the series.

In the second stage of our analysis, we intend to explore potential existence of interactions and interrelations of the stress indices, on a cross country level. In order to do this, we are going to employ VAR models, one of the most popular empirical approaches for analysing causal relationships between macroeconomic and financial variables. Since these models were propagated by Sims (1980), they became something like a workhorse for macroeconomic and macro-financial empirical investigation. Especially, in cases where prior economic theorizing or established causal relations between some economic or financial measures do not exist, the use of such a data driven econometric approach sounds natural.

In general, a VAR model consists of a number of equations, where all variables are considered as endogenous. Each equation incorporates lagged values of the dependent variable, in addition to lagged values of the rest of the variables. In the case of $k$ variables and $k$ error terms, the $\operatorname{VAR}(p)$ model is of the following form:

$$
F S I_{t}=\gamma_{1} F S I_{t-1}+\gamma_{2} F S I_{t-2}+\ldots+\gamma_{t} F S I_{t-\rho}+\varepsilon_{t}
$$

where $F S I_{t}=\left[F S I_{1, t} F S I_{2, t} \ldots F S I_{k, t}\right]^{\prime}$ is a vector of all the endogenous variables of

our model and $\varepsilon_{t}=\left[\begin{array}{llll}\varepsilon_{1, t} & \varepsilon_{2, t} & \ldots & \varepsilon_{k, t}\end{array}\right]^{\prime}$ is the vector of the error terms of the model, which are usually considered to be white errors, with a zero mean and constant variance. Finally, $\gamma_{i}(i=1, \ldots, t)$ are the $k x k$ matrices of the coefficients that need to 
be estimated by the model. For our case, we employ a VAR model with eleven equations ${ }^{17}$.

In the case of an unrestricted VAR model, the estimation can be done, using the usual OLS estimator. Of course, in order to have stable and robust results, it is necessary to test our series for their order of integration. Thus, before proceeding to our models' specification, we proceed with performing stationarity testing of the original series. The main test used is the augmented Dickey - Fuller (1979) test, while in case where the results were dubious, Phillips - Perron (1988) and KPSS (1992) test were also performed to verify whether or not a specified variable is stationary or not. The optimum number of lags for the equations is chosen by a number of lag selection criteria (the Akaike, the Schwarz and the Hannan - Quinn information criteria). Not all of these criteria should indicate the same number of lags for a model. As it is discussed by Luetkepohl (2011), Akaike criterion is usually the most tolerant (provides evidence for higher lag order), while Schwarz criterion chooses the shorter order. The general idea is to begin modelling with a moderate lag structure, which is what we do, given the time span covered and the number of equations involved in the estimations. Models' adequacy is examined through the inspection of the residuals behaviour ${ }^{18}$, even though, as commented by Luetkepohl (2011), residuals nonnormality is not a problematic situation for the validity of the inference conducted with these models.

The importance of this empirical investigation lies on the detection of channels of financial stress propagation from country to country. Canova (2007) mentions that inference through the estimated VAR coefficients is not an efficient approach to use these models. Instead, he suggests the use of impulse responses, as an efficient way to study the interrelations and causal relationships of the endogenous variables included in such a model. Impulse response analysis is the trace of a one unit innovation to one of the system's variable to itself and to the rest of the variables under investigation. This approach is really useful on pointing and analysing the effect of a structural change to any of the included financial stress indicators to the level of financial stress in the Euro Area countries. Here, we employ both the wellknown Cholesky decomposition approach, where the variables ordering (in terms of

\footnotetext{
${ }^{17}$ This is the case of country wide models, where we estimate models for financial stress index in national level.

${ }^{18}$ That is, whether they are normally distributed, heteroskedastic or autocorrelated.
} 
the sequence of the unexpected shocks involved) is important, while the generalized impulse responses, as proposed by Pesaran and Shin (1998), are employed as robustness checks in the aforementioned methodology. Here, the derived orthogonal set of innovations renders variables ordering obsolete.

\section{Eurozone's Financial Stress Narrative}

The following graph depicts the aggregate Euro Area- wide Financial Stress Index. As it is previously noted, the period covered is from January 2004 to August 2011. Thus, there is a wide coverage of, both, the initiation of the global financial crisis, its evolution and transformation to the current situation faced by the most indebted members of the monetary union. In general, the index indicates some minor fluctuations to its value, prior to 2007, without any of those presenting a serious threat for the stability of the markets. On the other hand, it is evident a slow but steady gradual increase in the level of financial stress, which reached its climax in the third quarter of 2008. The reason cannot be other than the Lehman Brothers collapse that took place in September 2008, with a number of major repercussions to the world financial system. In this case, the index reached it maximum value of 0.84 on October 2008, while it remained in high level until the end of the first quarter of 2009. In the meantime, the European Central Bank, through a number of unconventional monetary policies initiatives, tried to stabilize the increased systemic risk and uncertainty in the markets. For instance, right after the Lehman Brothers collapse and the, consecutive drying up of the interbank money market, the Eurozone's monetary authority proceeded to the acceptance of more financial assets, as collateral for the emergency funding, while on 2009 the covered bonds program was populated. Together with the decrease of the main refinancing rate by $\mathrm{ECB}$, it was expected and apparent from the graph above an abatement of the financial stress level. But this would not last for long, since the evolving crisis in Greece led to another outbreak of financial stress, on April and May 2010. The agreement on a rescue program seemed to tranquil the Eurozone economy, for a while, until another spike in the index came out as a consequence of the need for financial assistance and fiscal austerity measures, this time for Ireland (towards the end of 2010) and Portugal in early 2011. The financial stress remained 
excessively high, until the end of our sample, which includes the decision for the haircut on the Greek public debt. Similar patterns in the behaviour of the country specific financial stress indices are identified in the respective graph, in the appendix.

Figure 1: Level of Financial Stress for Euro Area

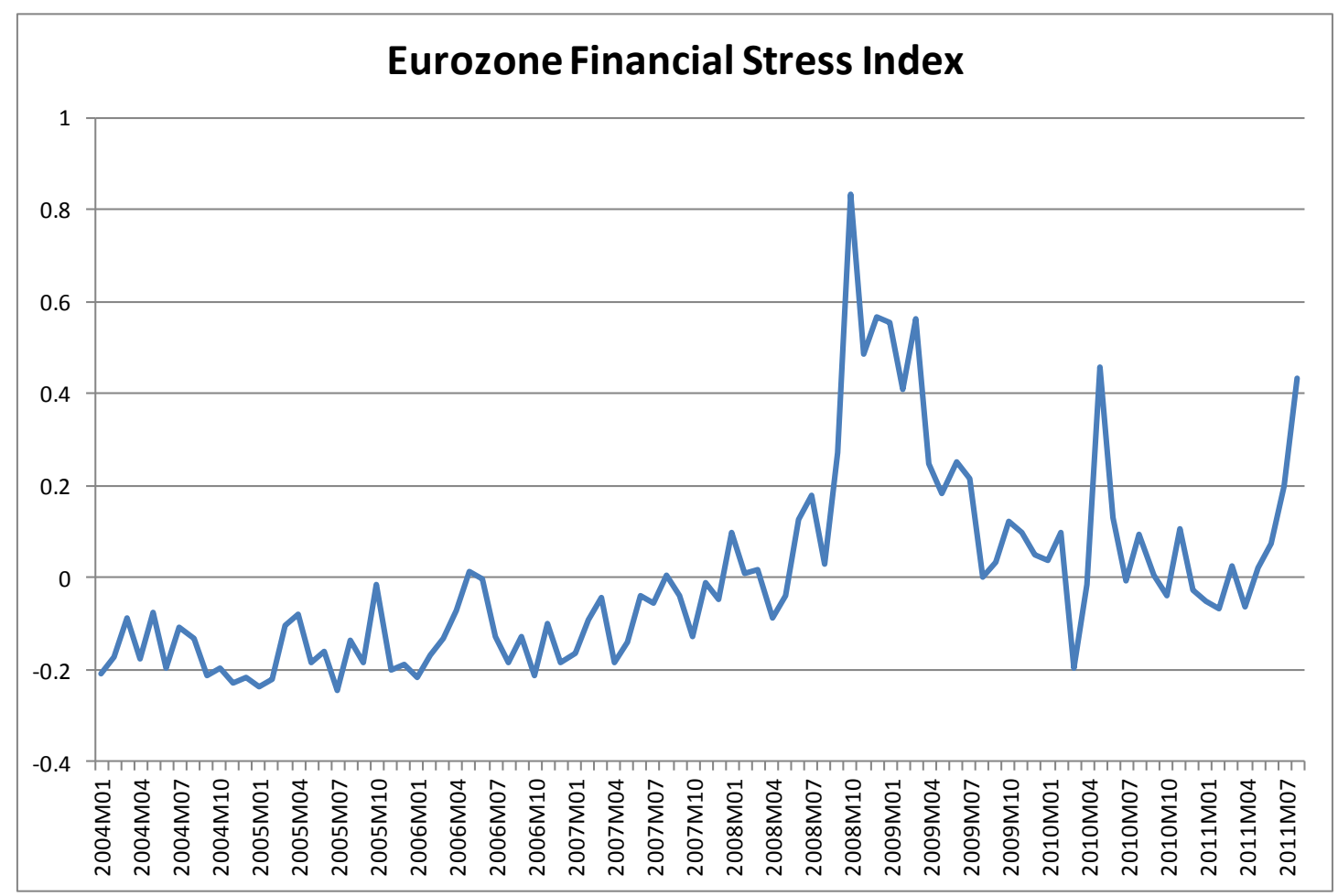

\section{Empirical Analysis}

In this section, we proceed to a more systematic analysis of the interconnections and the level of transmission of systemic stress from one country of the Eurozone to the others. In order to do this, a Vector Autoregressive (VAR) model is employed, which includes the financial stress indexes of the eleven Euro Area countries under examination. As a result, a model with eleven equations is used, the lags of which were chosen according to the usual well-known criteria ${ }^{19}$. Based on the different specifications, the residuals normality and autocorrelation tests, the model chosen to be presented is a VAR(1) model. The following graphs represent the impulse responses of this model, where the effects of a financial shock in each one of

${ }^{19}$ AIC, SIC, HQ criteria. 
the countries we examine are depicted. Additionally, two tables summarizing the effects presented in the impulse response graphs are provided. In there, a narrative short description of the different types of effects is provided, for the reader's convenience.

The results offer some quite interesting and intriguing illustrations for the Eurozone crisis. First of all, it seems that, in all cases, countries are mostly responsive to their own financial shocks. With the exceptions of Finland, Belgium, Italy and Greece, the excessive financial stress soon returns to its prior levels. In case of Greece, the effect lasts for almost a year after the initial shock, while Finland's one is even more persistent. Additionally, some degree of regionalism is apparent in the results. According to the impulse responses, the peripheral debt-ridden countries are more responsive to the increasing financial stress of the same group of countries, while the similar effect is sketched for the major Euro Area countries, notably Germany, France, Netherlands and Finland. This implies the existence of disparities in the way that financial shocks reflect on the union's member countries, while it can be also an indication to ECB for adoption of different policies in countries that face divergent financial and economic obstacles. Another important finding, which appears to contradict the mainstream view on the current crisis, is the minor effects that increasing financial stress in Greece and Portugal seem to have to the rest of the Eurozone countries. According to the impulse response graphs above, there is no evidence of transmission of heightening financial risk from these troubled countries to the rest. On the other hand, the Italian financial upheaval has some effect on most countries, although not always in the expected way (negative effect on the level of financial stress). In any case, the previously mentioned finding, for the minor role of Greece and Portugal in the crisis transmission is concurrent by recent research, for instance Gonzalez-Hermosillo and Johnson (forthcoming). In this work, the authors emphasize the fact that, according to their stochastic volatility model, most of the risk associated with the current Eurozone countries is country specific, while they could not provide any hard evidence to blame Greece or Portugal as major channels of crisis contagion to the rest of the Euro Area. 

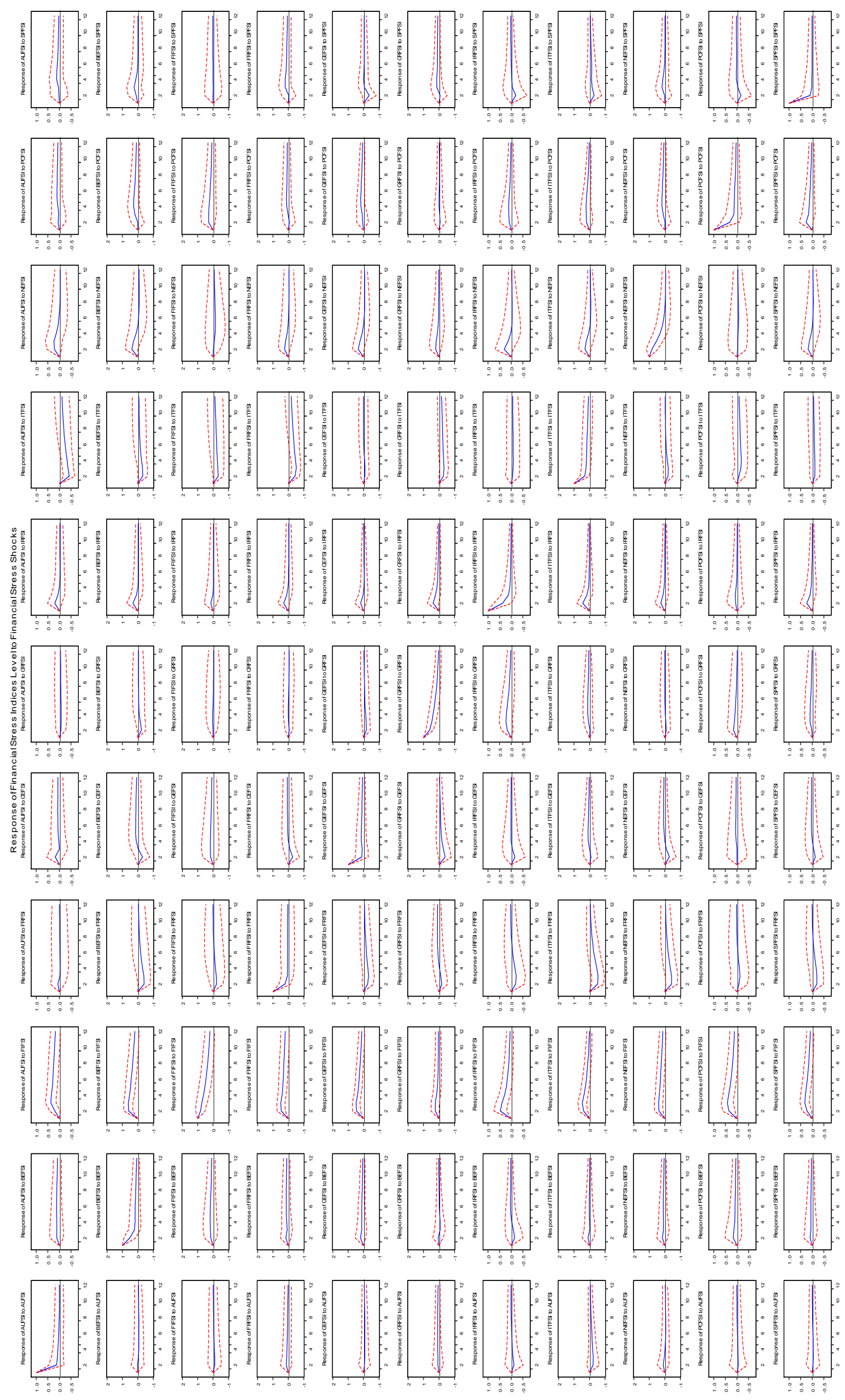


\section{Further Evidence and Robustness Checks}

In order to examine our results resilience, we provide further evidence in favour of our baseline model results. Such evidence is provided in several ways. Firstly, a multivariate granger causality test is applied, examining the direction of potential transmission channels on a country level. Secondly, we adopt an alternative impulse responses' approach allowing the results to be irrelevant of the ordering we apply. Then, we exclude all balance-sheet data from our dataset, regarding the banking sector, allowing our analysis to be implemented for high frequency-market data. We also consider whether the presence of a US financial stress index or the use of an extended sample would alter the major findings of our work. Finally, we split the sample in pre- and post-crisis period, in order to reveal potential discrepancies between the two time periods.

The block exogeneity test refers to a multivariate Granger causality test, providing further evidence concerning the interconnection of the financial stress indices. As it is well known, Granger (1969) examines whether a variable $\mathrm{x}$ is better explained from an equation including, both past values of $\mathrm{x}$ itself, along with lagged values of another variable, say $\mathrm{y}$. In equational form, for the case of two variables (x and y) it should be:

$$
\begin{aligned}
& y_{t}=c+\beta_{1} y_{t-1}+\ldots+\beta_{i} y_{t-i}+\delta_{1} x_{t-1}+\ldots+\delta_{i} x_{t-i}+\varepsilon_{t} \\
& x_{t}=c+\beta_{1} x_{t-1}+\ldots+\beta_{i} x_{t-i}+\delta_{1} y_{t-1}+\ldots+\delta_{i} y_{t-i}+u_{t}
\end{aligned}
$$

where the number of lags included in each equation is determined from the usual information criteria. Using F-type statistics, they null hypothesis examined is whether y does not Granger cause x (and vice versa). In case of a VAR model, with more than two endogenous variables, the Granger causality testing procedure remains similar. The block-exogeneity test is useful for testing whether the lagged values of a variable do not Granger cause the dependent variable. It is very similar to the aforementioned Granger causality test, adapted for the case where more than one lagged variables are included in the model's equations. In order to perform this test, the coefficients of the 
lagged values of the variable to be tested, are set equal to zero and a likelihood ratio statistic is used to evaluate the potential causality relationship of this variable with the regressand. Using this test, extra evidence is provided, regarding the existence of potential financial risk transmission channels between the Eurozone economies and their respective markets.

\section{[Insert table 2 about here]}

In the table above, the respective p-values, indicating the statistical significance of the potential causal relationship between the variables under examination, are reported. The hypothesis tested is whether the financial stress of each country reported in every row does not Granger cause the level of financial stress for each country depicted on every column. As it is evident, there is no any evidence for financial stress transmission within the Euro Area economies. The only notable exception is Finland, which presents a peculiar, statistical significant effect towards all the other economies. Especially, for the case of core countries, the causal effect is very significant. Italian stress index also granger causes to a number of economies, with bidirectional effects to exist with Ireland, France and Finland. Again, there is no any evidence for Greek and Portuguese financial stress to transmit to the rest of the monetary union. The same holds for Spain.

Then, an alternative specification for the estimation of the relevant impulse response functions is provided. This is the generalized version of impulse responses, as proposed by Koop et al. (1996) and Pesaran and Shin (1998). This is an alternative to shocks' orthogonalization, proposed by Sims (1980). In this respect, there is no need to apply any judgemental decision on the variables ordering. The produced shocks are invariant to ordering and the outcome is robust. Regarding the generalized impulse functions, the graphs, are provided in the following graph. Inspecting the relevant plots, one can concur on their unanimity with the initial impulse response analysis.

\section{[Insert figure 3 about here]}

A final robustness check involves the exclusion of all bank balance sheet data we used in the financial stress indices construction. Since the aforementioned have a 
much lower frequency, compared to the market level data, it is questionable whether their presence might affect the variability of the produced aggregate indexes. Such lower variability might, in turn, have an effect on the estimated VAR model and the produced impulse responses. Hence, we recalculated the financial stress indexes for each country, only this time without the bank balance sheet data. Based on the new systemic risk indices, a vector autoregressive model was estimated and the relevant generalized impulse responses are presented in the following graph. For most cases again, the financial stress transmission remains to very low level, indicating a lack of sustainable and persistent systemic risk effect towards any of the countries discussed here. The results of our baseline model are confirmed by this alternative version of aggregate systemic risk indicators.

\section{[Insert figure 4 about here]}

Figure 5 presents the generalized impulse responses for the case of the extended sample use. Since our original model covers a period up to the third quarter of 2011, we decide to extend the sample until recently (September 2013). The rationale is to check whether the inclusion of a longer time horizon have any effect on the findings of our baseline approach. As it is evident from the graphs, this is not the case. The responses' regionalism is still evident, especially among the core Euro Area economies. On the other hand, Ireland presents a somehow strong role as financial stress transmitter, towards the other economies of the union. In any case, the results remain robust, without any major discrepancies between the two different sample sizes.

\section{[Insert figure 5 about here]}

The employment of a US financial stress index in our model, in order to capture potential global influences within the Eurozone countries financial stress level, do not alter the findings of our baseline approach. The financial stress index used for the United States is the one developed by Hakkio and Keetong (2009). Based on these economists' work, the Kansas City Fed created and maintains a financial stress index to monitor the evolution of the financial conditions in the American economy. The reason for choosing this index among many others is its resemblance, in theoretical 
underpinnings and construction approach, with the indexes we produced for the Euro Area countries. Thus, our model is extended, including Kansas City Fed FSI as an additional endogenous variable. Based on this, it is clear that US financial stress level remains immune to Eurozone effects, while the opposite is not always the case. Some of the most advanced economies in Euro Area are susceptible to increasing financial distress from US. This spill-over effect is of low magnitude but persistent. This situations is not verified for the case of peripheral economies. The presence of US financial stress in the model does not affect the stress transmission level between the Eurozone economies.

\section{[Insert figure 8 about here]}

The examination of potential differences in the interconnections of the euro economies before and after the global crisis outbreak does not bring any surprise. September 2008 is chosen as the cut-off point, where the global financial crisis reached its peak, due to the Lehman Brothers collapse. Once again, Greece does not emerge as financial stress transmitters to the common currency area, irrespective of the time period investigated. On the same time, Spain, which has some positive and persistent effect on a number of countries in the pre-crisis period, do not show such behaviour in the second sub-sample. This is justifiable, given the unprecedented interventional policies implemented by the Euro Area authorities. Interestingly, Italy exhibits persistent effects in both periods, indicating the importance of the conditions in this economy for the whole euro union.

\section{Concluding Remarks}

Aim of this work is the study of financial stress level of the countries that constitute the Euro Area. In this way, an early warning indicator of forthcoming financial turmoils can be constructed, which is able to provide timely indications of potential financial crashes. Additionally, a VAR model is employed, so that indications on the existence or not of financial stress transmission within the Eurozone countries can be provided. According to our results, countries are mostly responsive to their own financial shocks, while a degree of regionalism is evident, in 
the sense that peripheral countries are more susceptible to their financial stress, while the same holds for the core Eurozone countries. Finally, in contrast to common wisdom, financial conditions in Greece and Portugal do not seem to affect the rest of the Euro Area, at least in the degree that Italy and Ireland do. These findings remain consistent and unaltered to a number of robustness checks. 


\section{References}

Angelopoulou, E., Balfoussia, H. and Gibson, H. (2012), "Building a Financial Conditions Index for the Euro Area and selected Euro Area Countries: what does it tell us about the crisis?", Bank of Greece Working Paper, no.147

Brave, S. and A. Butters (2011), "Monitoring Financial Stability: A Financial Conditions Index Approach", Federal Reserve Bank of Chicago Economic Perspectives, 1Q/2011

Canova, F. (2007), Methods for Applied Macroeconomic Research, Princeton University Press

Carlson, M., Kurt L., and Nelson. W., (2012), "Using Policy Intervention to Identify Financial Stress", Board of Governors of the Federal Reserve System Finance and Economics Discussion Series, no. 02

Debuque-Gonzales, M. and M. Socorro Gochoco-Bautista (2013), "Financial Conditions Indexes for Asian Economies", Asian Development Bank Economics Working Paper Series, no. 333

Demirguc-Kunt, A. and Detragiache, E. (1998), "The Determinants of Banking Crises in Developing and Developed Economies", IMF Staff Papers, vol. 45(1)

Dickey, D. A. and Fuller, W. A. (1979), "Distribution of the Estimators for Autoregressive Time Series with a Unit Root", Journal of the American Statistical Association, vol. 74: pp. 427-431

Granger, C. W. (1969), "Investigating Causal Relations by Econometric Models and Cross-Spectral Methods", Econometrica, vol. 37: pp. 424-438

Grimaldi, M. (2010), "Detecting and Interpreting Financial Stress in the Euro Area", ECB Working Paper Series, no. 1214

Hakkio, C. and W. Keeton (2009), "Financial Stress: What is it, How Can it be Measured, and Why does it matter?", Federal Reserve Bank of Kansas Economic Review

Hodrick, R. J. and Prescott, E. C. (1997), "Postwar U.S. Business Cycles: An Empirical Investigation", Journal of Money, Credit and Banking, vol. 29(1): pp. 1-16 
Hollo, D., Kremer, M. and Lo Duca, M. (2012), "CISS - A composite indicator of systemic stress in the financial system”, ECB Working Paper Series, no. 1426

Illing, M. and Y. Liu (2006), "Measuring Financial Stress in a Developed Country: An Application to Canada", Journal of Financial Stability, vol. 2(3): pp. 243-265

Kaminsky, G., Lizondo S. and Reinhart C. (1998), "Leading Indicators of Currency Crises", IMF Staff Papers, vol. 45(1)

Kliesen, K. L., Owyang, M. T. and E. K. Vermann (2012), "Disentangling Diverse Measures: A Survey of Financial Stress Indexes”, Federal Reserve Bank of St. Louis Review, September/October

Koop, G., Pesaran, M. H. and S. M. Potter (1996), "Impulse Response Analysis in Nonlinear Multivariate Models", Journal of Econometrics, vol. 74: pp. 119 -147

Kwiatkowski, D., Phillips, P. C., Schmidt, P. and Shin, Y. (1992), “Testing the Null Hypothesis of Stationary against the Alternative of a Unit Root", Journal of Econometrics, vol. 54: pp. 159-178

Lee, H. W., Xie, Y. A. amd Yau, J. (2011), “The Impact of Sovereign Risk on Bond Duration: Evidence from Asian Sovereign Bond Markets", International Review of Economics and Finance, vol. 20(3): pp. 441-451

Lee, H. W., Xie, Y. A. amd Yau, J. (2012), "Effects of Sovereign Risk on Duration: Evidence from European and Latin American Sovereign Bond Markets", Available at SSRN: http://ssrn.com/abstract=2139752 or http://dx.doi.org/10.2139/ssrn.2139752

Louzis, D. and Vouldis, A. (2012), "A methodology for constructing a Financial Systemic Stress Index: an application to Greece”, Economic Modeling, vol. 29(4)

Louzis, D., Vouldis, A. and Metaxas, V. (2012), "Macroeconomic and bank-specific determinants of non-performing loans in Greece: A comparative study of mortgage, business and consumer loan portfolios", Journal of Banking and Finance, vol. 36(4): pp. $1012-1027$ 
Luetkepohl, H. (2011), "Vector Autoregressive Models", EUI Working Papers Series, no. 30

Melvin, M. and Taylor, M. (2009), "The Crisis in the Foreign Exchange Market", Journal of International Money and Finance, vol. 28(8): pp. 1317-1330

Mishkin, F. S. and Estrella, A. (1998), "Predicting U.S. Recessions: Financial Variables as Leading Indicators", The Review of Economics and Statistics, vol. 80(1): pp. $45-61$

Morales, M. and Estrada D. (2010), “A Financial Stability Index for Colombia”, Annals of Finance, 6:555-581

Nelson, W., and Perli, R. (2005), "Selected indicators of financial stability", Irving Fisher Committee's Bulletin on Central Bank Statistics, 23, 92-105

Oet, M., Eiben, R., Bianco, T., Gramlich, D., and S. Ong (2011), "The Financial Stress Index: Identification of Systemic Risk Conditions", Federal Reserve Bank of Cleveland Working Paper Series, no. 11-30

Oet, M., Eiben, R., Gramlich, D., Miller, G. and S. Ong (2010), "SAFE: An Early Warning System for Systemic Banking Risk", in Conference: "Beyond the Financial Crisis: Systemic Risk, Spillovers and Regulation", Dresden

Osorio, C. Pongsaparn, R. and D. F. Unsal (2011), "A Quantitative Assessment of Financial Conditions in Asia", IMF Working Paper Series, no. 170

Pesaran, H. M. and Y. Shin (1998), "Generalized Impulse Response Analysis in Linear Multivariate Models", Economics Letters, vol. 58(1): pp. 17 - 29

Phillips, P. C. and Perron, P. (1988), "Testing for a Unit Root in Time Series Regression", Biometrika, vol. 75: pp. 335-346

Puddu, S. (2008), “Optimal Weights and Stress Banking Indexes”, HEC-Universite de Lausanne, mimeo

Sandahl, J. F., Holmfeldt, M., Ryden, A. and Stromqvist, M. (2011), "An index of financial stress for Sweden", Sveriges Riksbank Economic Review, no. 2

Sims, C. A. (1980), "Macroeconomics and Reality", Econometrica, vol. 48(1): pp. 148

Slingenberg, J. W. and de Haan, J. (2011), "Forecasting Financial Stress", De Nederlandsche Bank Working Papers Series, no. 292 


\section{Appendix}

Figure 2: Level of Financial Stress for each Eurozone Country

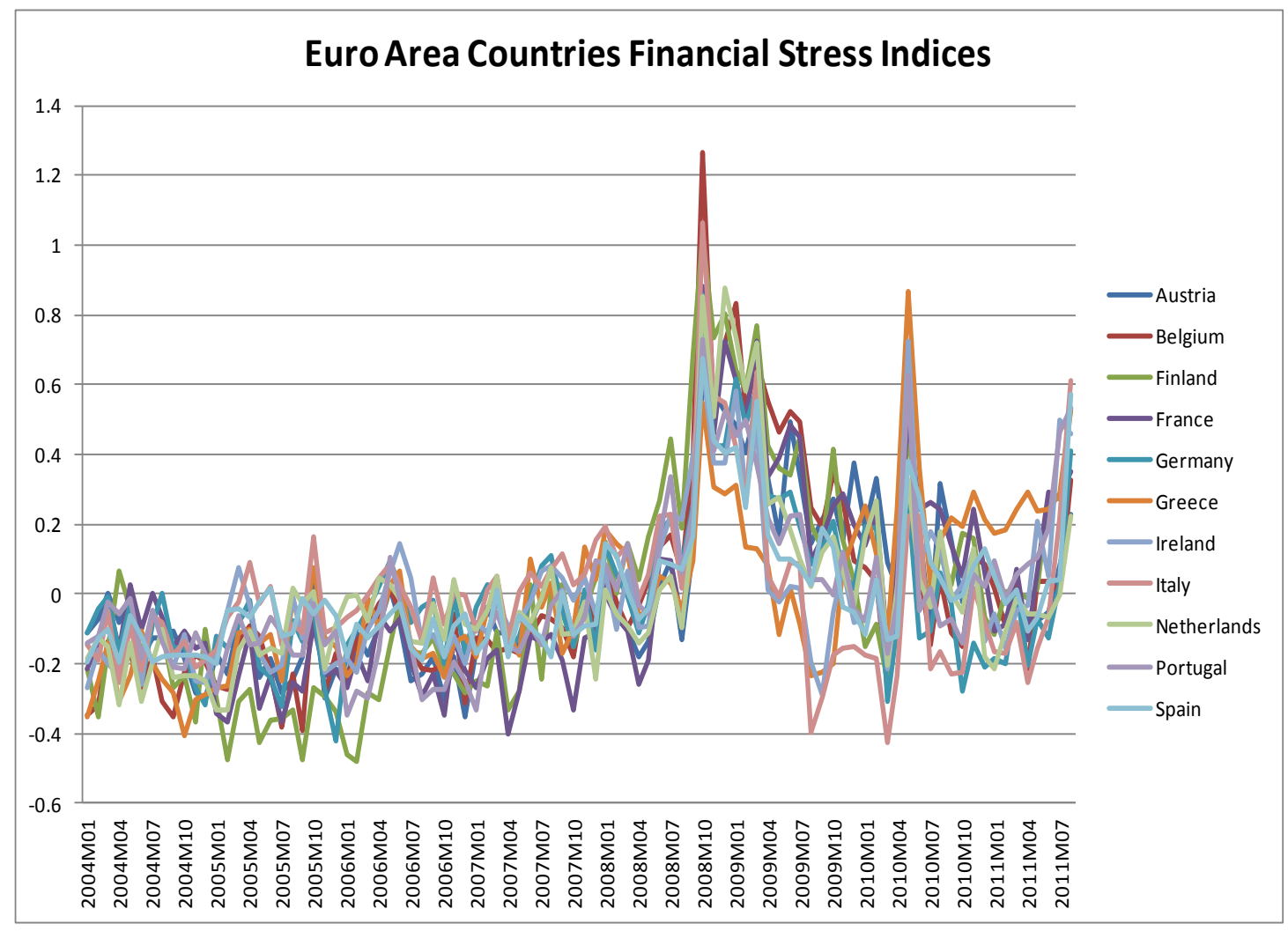




\section{Table 1: Summary of Financial Stress Shocks in Eurozone Countries}

Effects of Financial Stress Shocks in Eurozone Countries - 1 (FSI - 1 case)

\begin{tabular}{|c|c|c|c|c|c|}
\hline Response to & Greece & Portugal & Spain & Ireland & Italy \\
\hline Austria & negligible & negligible & negligible & slightly positive - minor & negative \\
\hline Belgium & negligible & slightly positive - minor & slightly positive - minor & slightly positive - minor & negative - minor \\
\hline Finland & negligible & slightly positive - minor & negligible & negligible & negative \\
\hline France & negligible & negligible & slightly positive - minor & slightly positive - minor & negative \\
\hline Germany & slightly negative - minor & negligible & negligible & slightly positive - minor & negligible \\
\hline Greece & --- & negligible & negligible & slightly positive - minor & negative \\
\hline Ireland & positive & slightly positive - minor & negligible & --- & negligible \\
\hline Italy & negligible & slightly positive - minor & slightly positive - minor & slightly positive - minor & --- \\
\hline Netherlands & negligible & negligible & negligible & slightly positive - minor & negative - minor \\
\hline Portugal & slightly positive - minor & --- & negligible & negligible & negative - minor \\
\hline Spain & negligible & slightly positive - minor & --- & slightly positive - minor & negative - minor \\
\hline
\end{tabular}


Table 2: Summary of Financial Stress Shocks in Eurozone Countries

\begin{tabular}{|c|c|c|c|c|c|c|}
\hline Response to & Austria & Belgium & Finland & France & Germany & Netherlands \\
\hline Austria & --- & negligible & positive & negligible & negligible & slightly positive - minor \\
\hline Belgium & negligible & --- & positive & negative & negligible & slightly positive - minor \\
\hline Finland & negligible & negligible & --- & negligible & negligible & negligible \\
\hline France & negligible & negligible & positive & -- & negligible & negligible \\
\hline Germany & negligible & negligible & positive & negative & --- & negligible \\
\hline Greece & negligible & negligible & negligible & negligible & negligible & negligible \\
\hline Ireland & negligible & negligible & positive & negative & negligible & negligible \\
\hline Italy & negligible & negligible & negligible & negative & negligible & negligible \\
\hline Netherlands & negligible & negligible & negligible & negative & negligible & --- \\
\hline Portugal & negligible & negligible & positive & negligible & negligible & negligible \\
\hline Spain & negligible & negligible & positive & negligible & negligible & negligible \\
\hline
\end{tabular}

Note: This is a summary of the impulse responses, produced using the baseline VAR model where the variance - equal financial stress indices are used. The table is read column by column, where each one of the latter represents a specific shock and each row shows the respective receiver of the shock (and the producing result). 


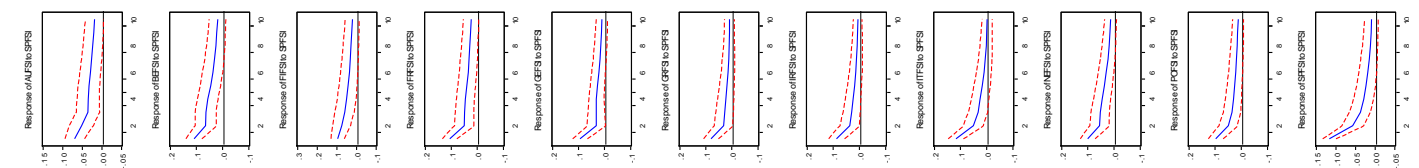

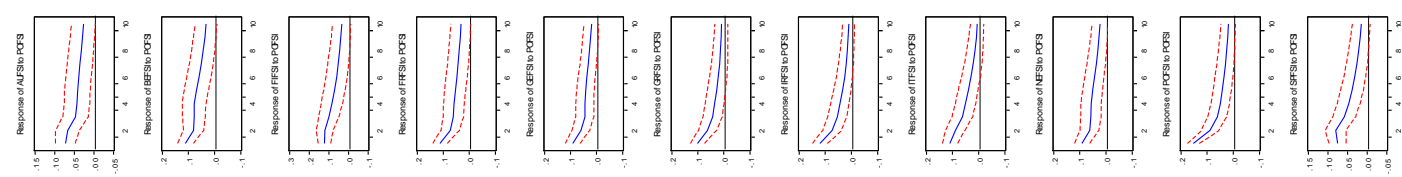

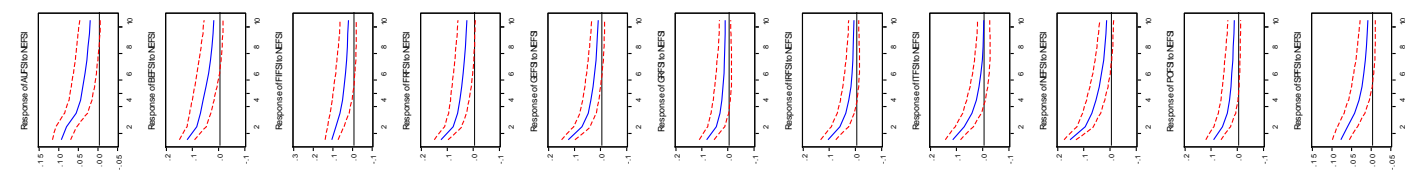

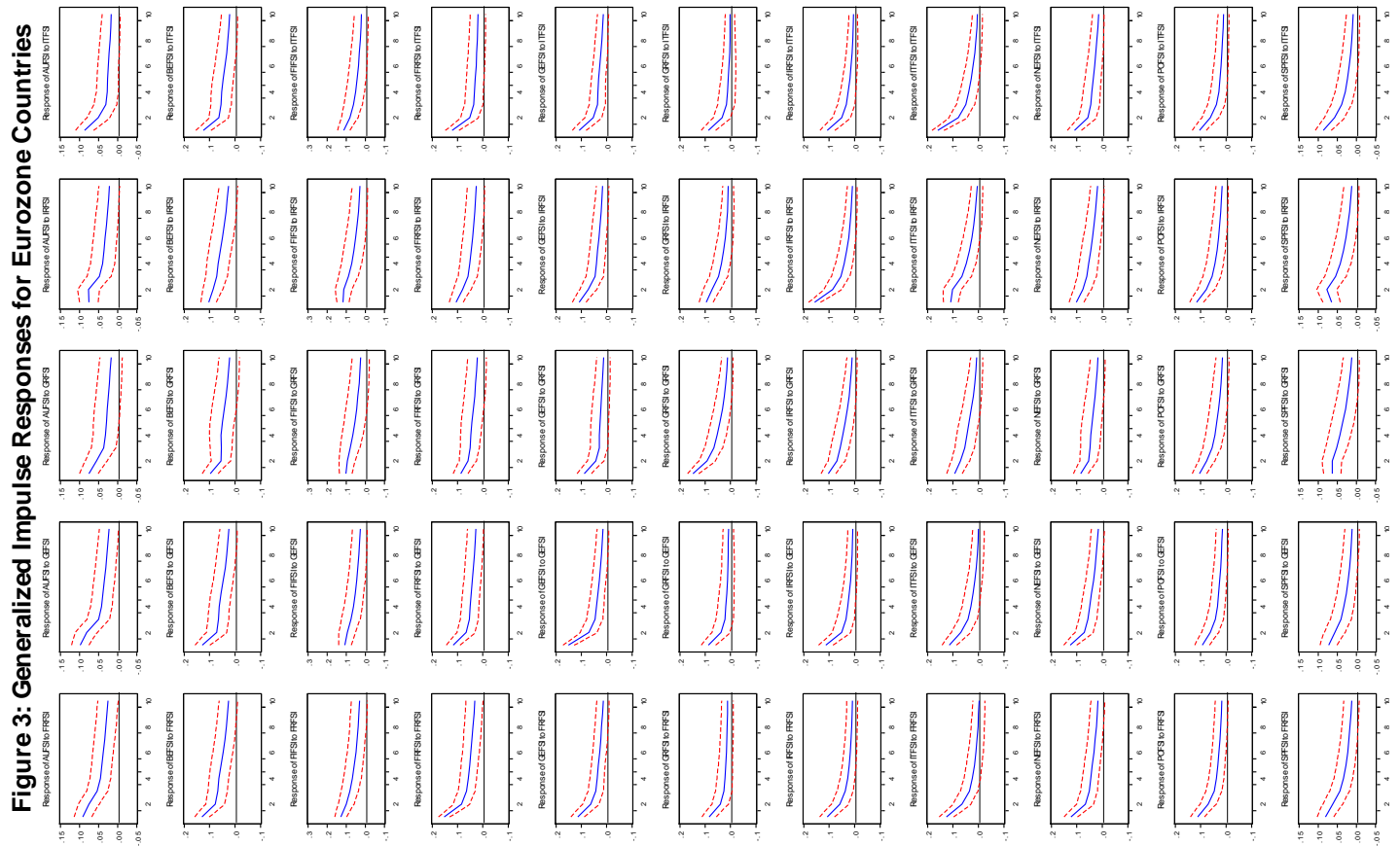

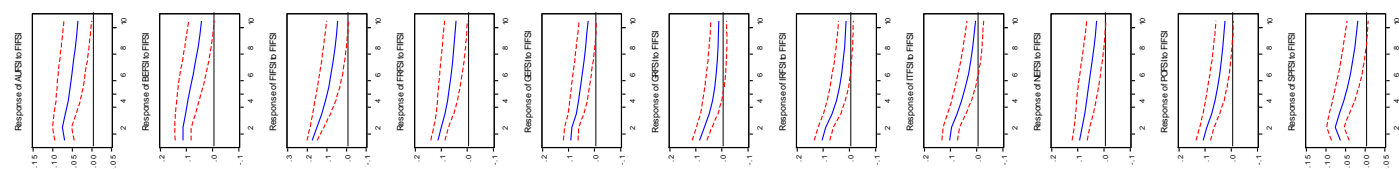

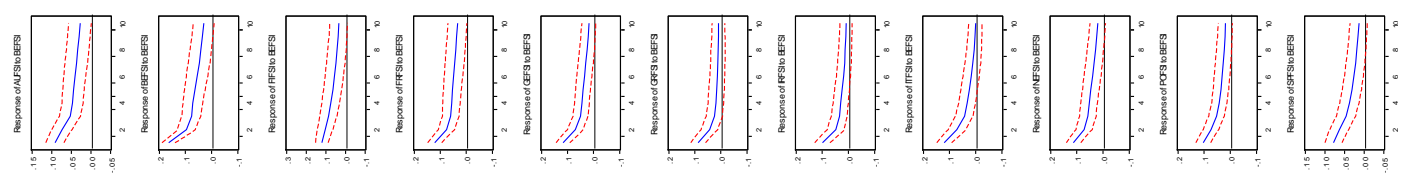

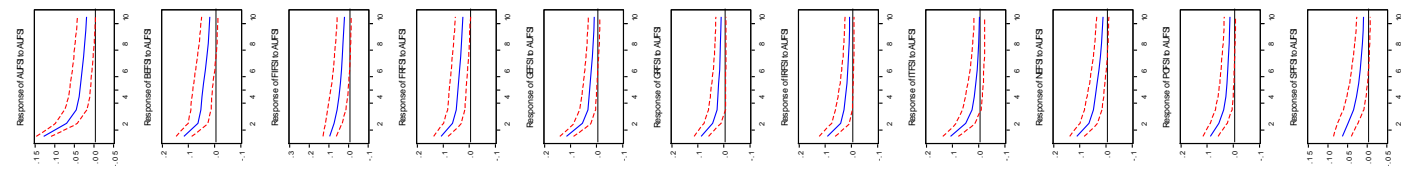




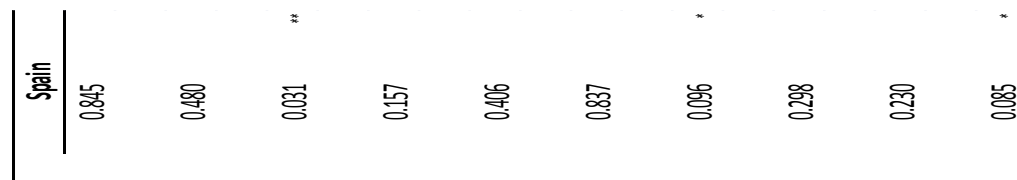

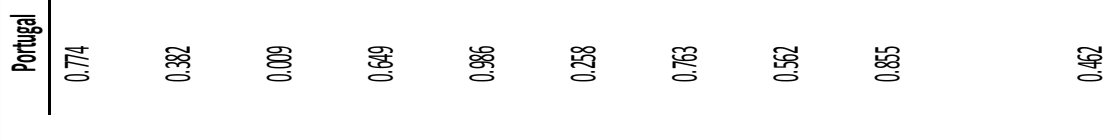

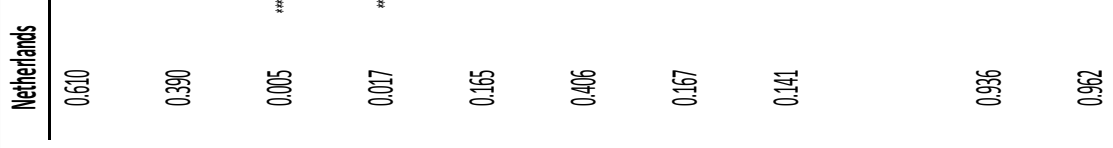

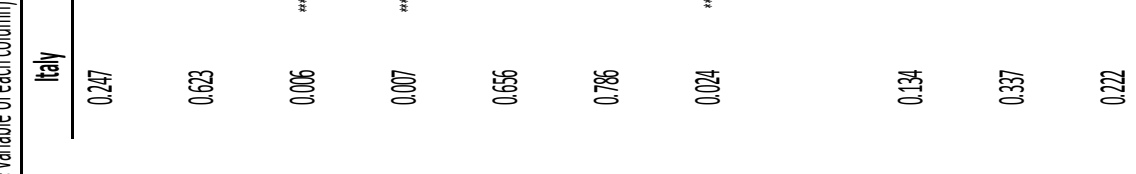

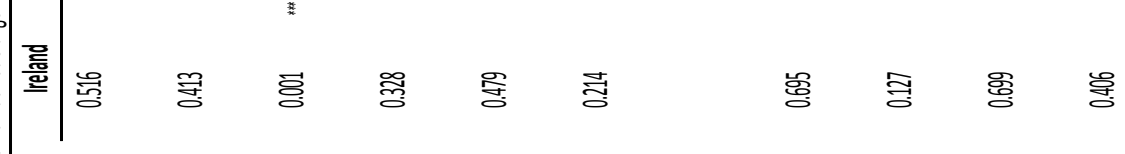

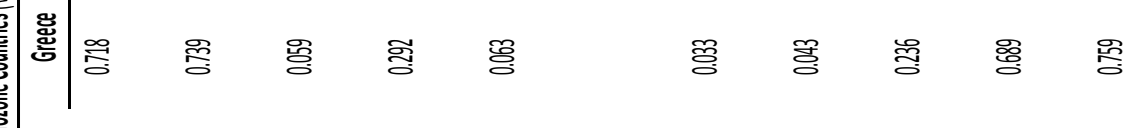

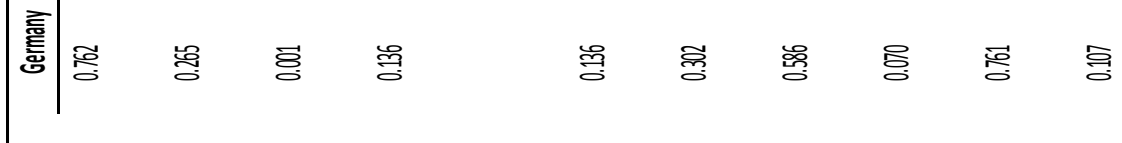

产虽

惡

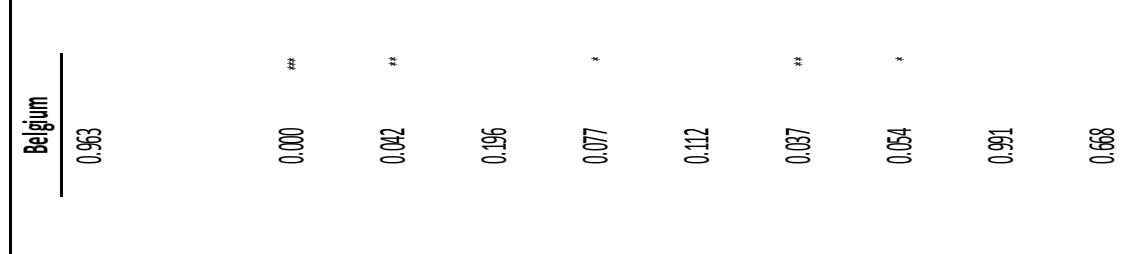

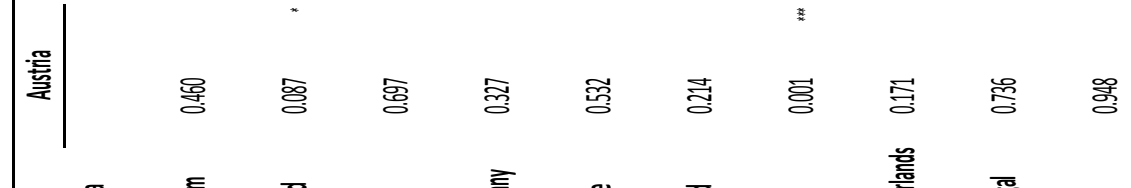

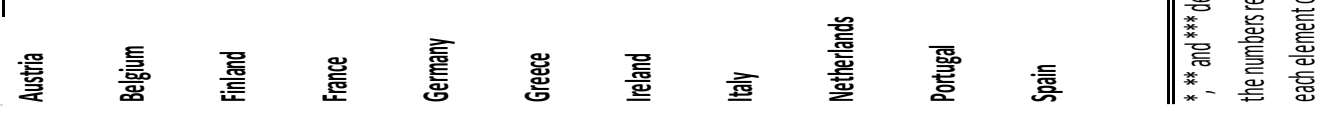


DD:
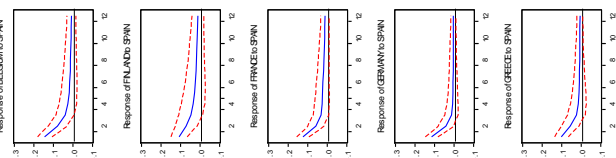

:
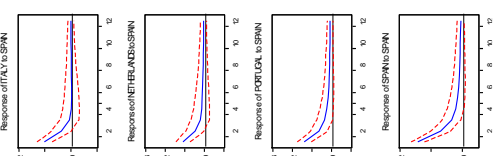

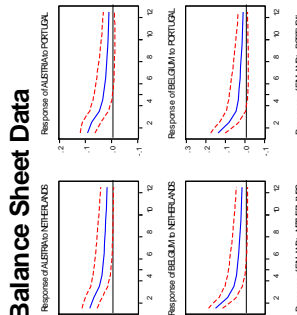
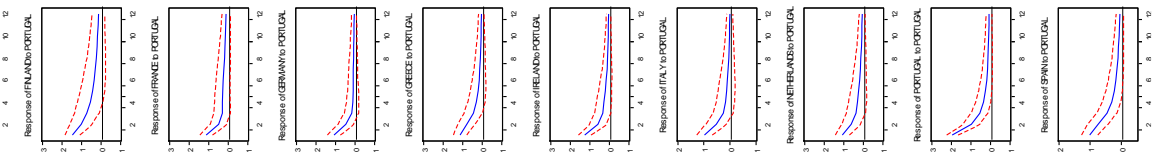

秀
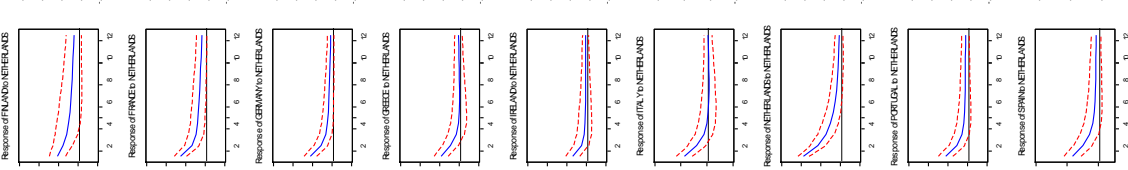

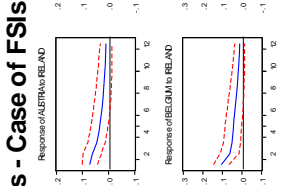
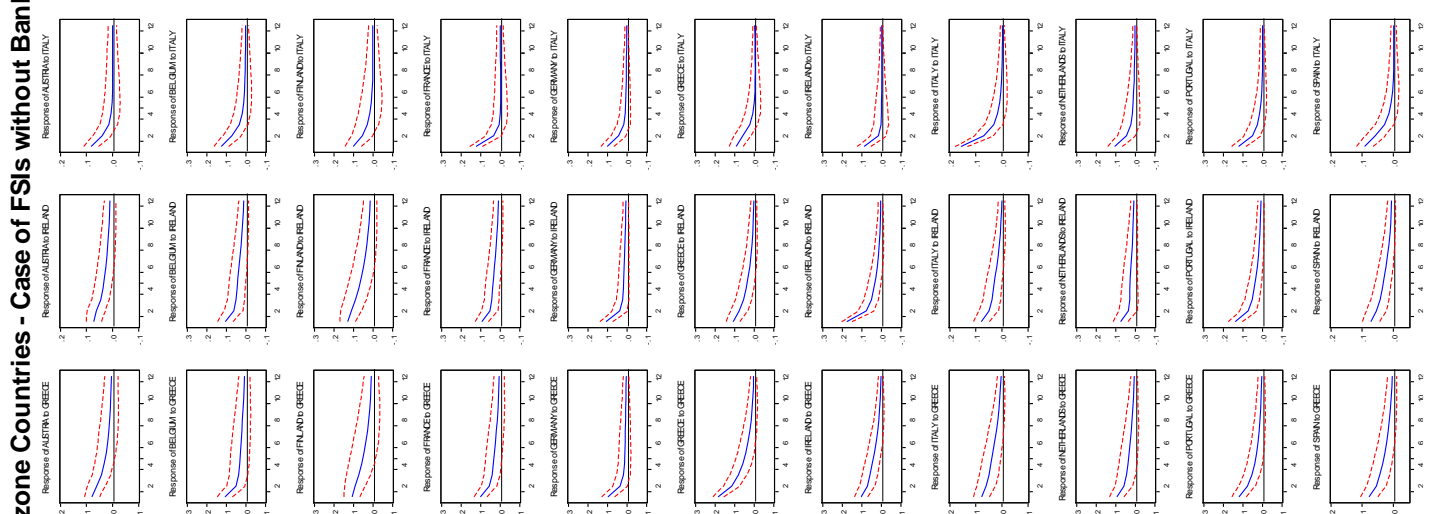

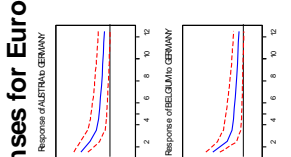
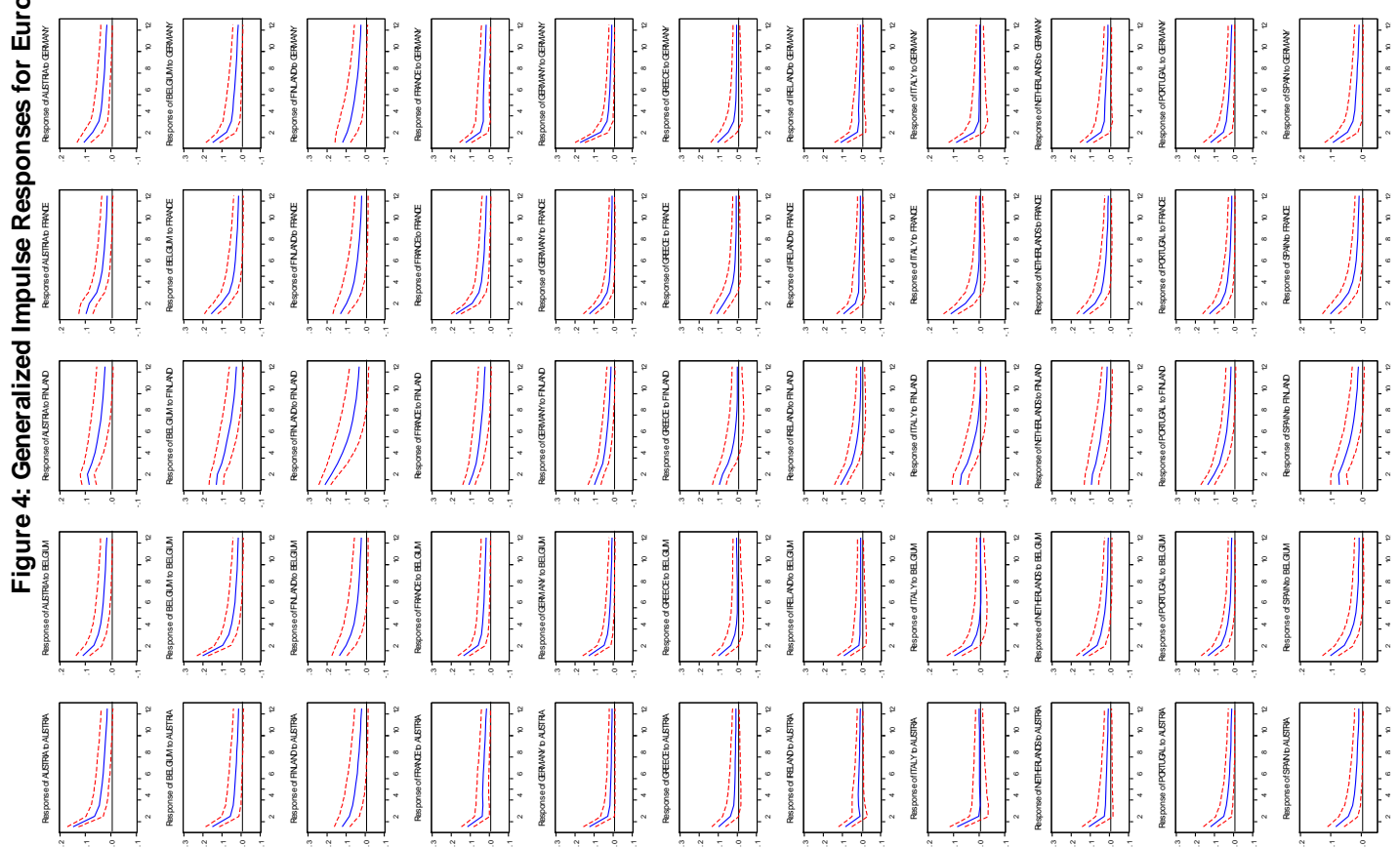

[]
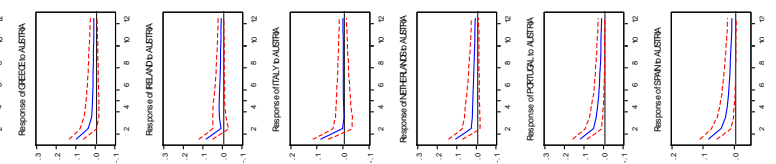

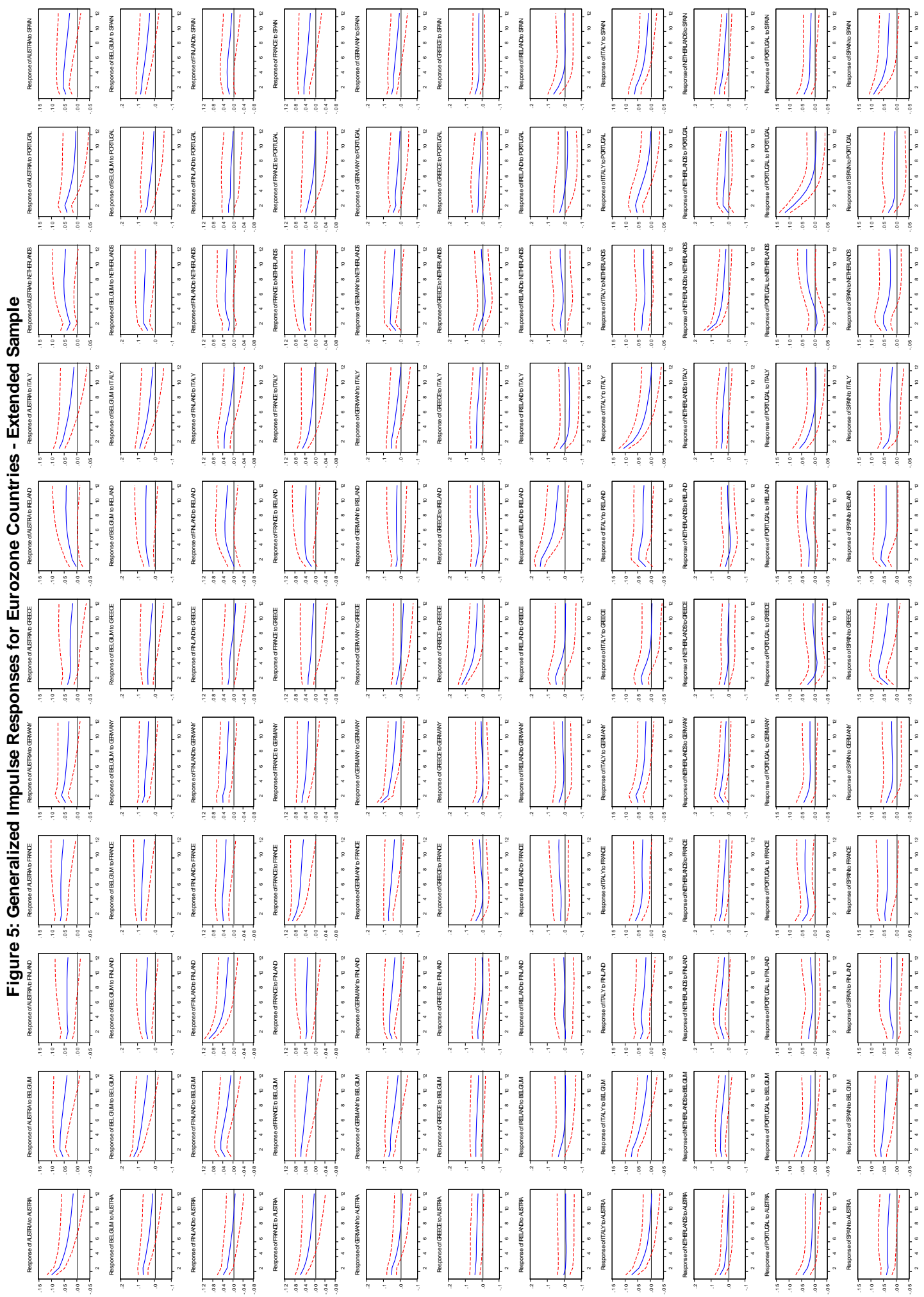

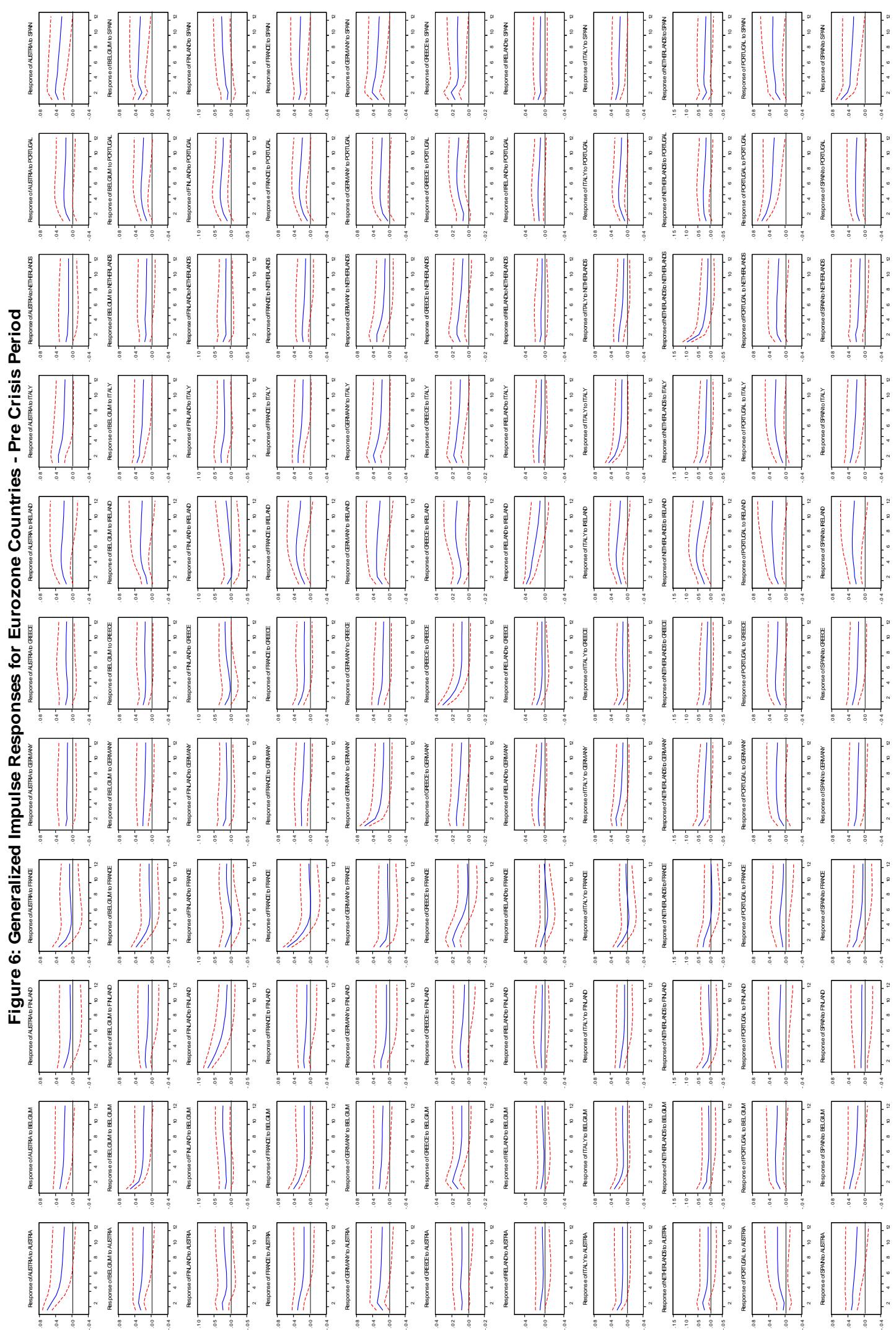

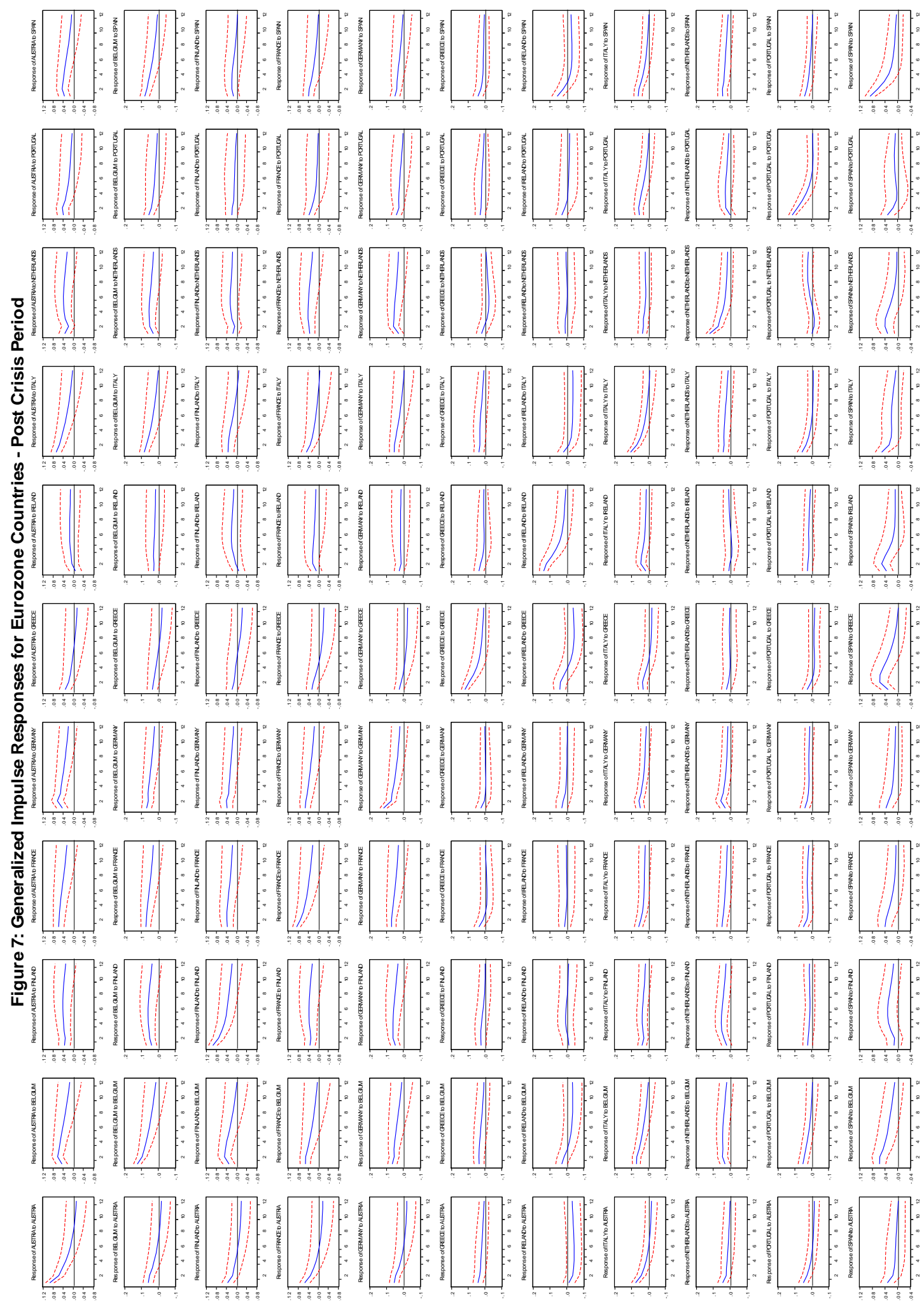

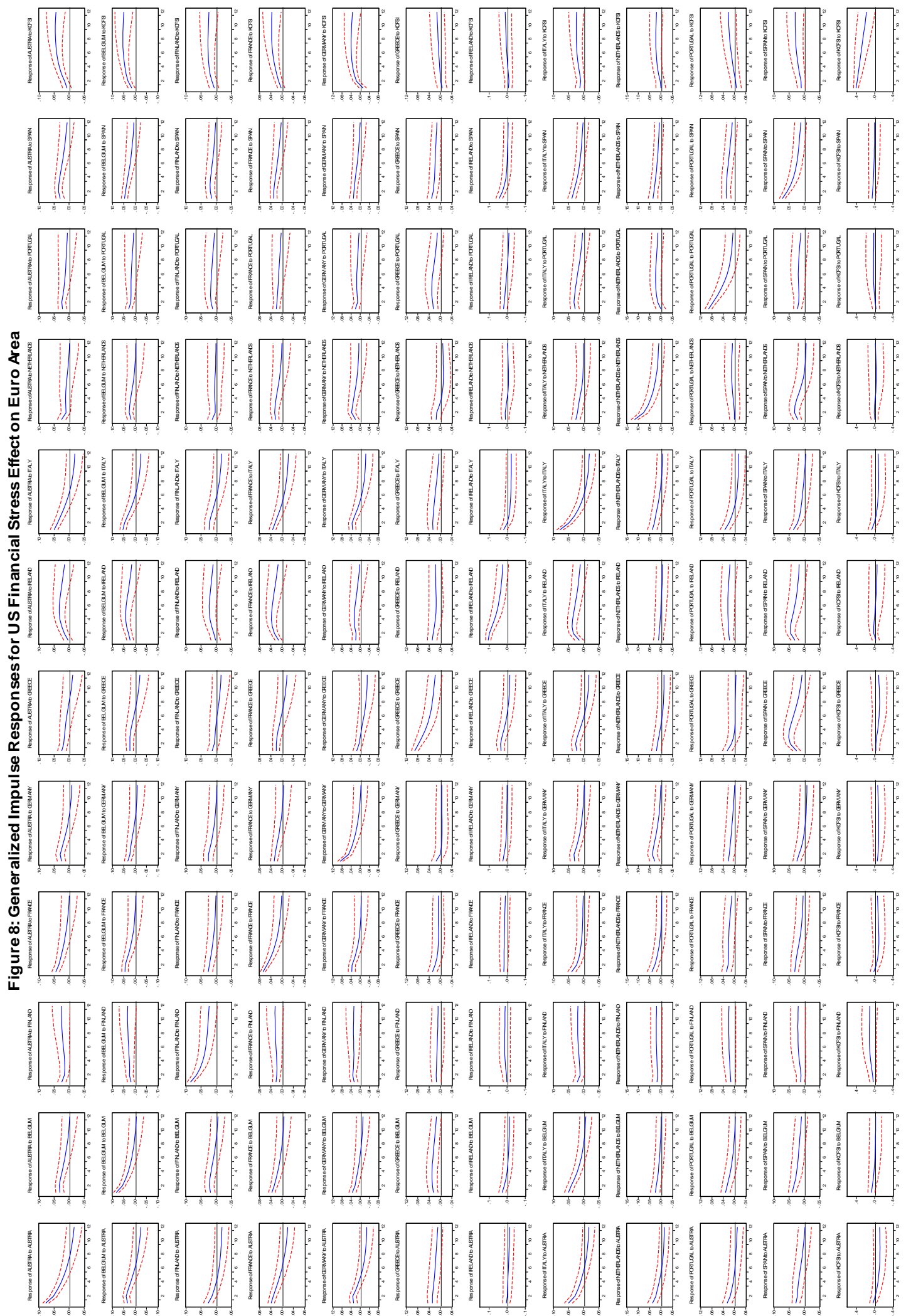